\title{
The effect of aging and resveratrol supplementation on bone mass and strength in hindlimb suspended male rats
}

\author{
Stephanie Wright \\ West Virginia University
}

Follow this and additional works at: https://researchrepository.wvu.edu/etd

\section{Recommended Citation}

Wright, Stephanie, "The effect of aging and resveratrol supplementation on bone mass and strength in hindlimb suspended male rats" (2010). Graduate Theses, Dissertations, and Problem Reports. 2987. https://researchrepository.wvu.edu/etd/2987

This Thesis is protected by copyright and/or related rights. It has been brought to you by the The Research Repository @ WVU with permission from the rights-holder(s). You are free to use this Thesis in any way that is permitted by the copyright and related rights legislation that applies to your use. For other uses you must obtain permission from the rights-holder(s) directly, unless additional rights are indicated by a Creative Commons license in the record and/ or on the work itself. This Thesis has been accepted for inclusion in WVU Graduate Theses, Dissertations, and Problem Reports collection by an authorized administrator of The Research Repository @ WVU. For more information, please contact researchrepository@mail.wvu.edu. 


\title{
The Effect of Aging and Resveratrol Supplementation on Bone Mass and Strength in Hindlimb Suspended Male Rats
}

\author{
Stephanie Wright \\ A thesis submitted to Davis College of Agriculture, Natural Resources \& Design \\ at West Virginia University \\ in partial fulfillment of the requirements for the degree of \\ Master of Science \\ in \\ Human Nutrition
}

Janet C.L Tou, PhD., Chair

Cindy Fitch, PhD., RD.

Susan Partington, PhD., RD

Division of Animal and Nutritional Sciences

West Virginia University

Morgantown, West Virginia

2010

Keywords: resveratrol, bone health, bone mineral content, bone mineral density, bone strength, mature male rats, old male rats 


\section{ABSTRACT \\ The Effect of Aging and Resveratrol Supplementation on Bone Mass and Strength in Hindlimb Suspended Male Rats}

\section{Stephanie Wright}

Resveratrol has recently become a popular dietary supplement because of its potential for reducing the effects of aging and various age-related diseases. However, few studies have investigated the role of resveratrol in improving bone loss associated with aging. It has been widely reported that mechanical unloading increases bone loss. The elderly experience a prevalence of reduced mechanical loading due to declining activity levels and increased incidence of bed rest. In rats, hind-limb suspension (HLS) simulates mechanical unloading of bone. Therefore, the objective of this study was to examine the effects of aging and resveratrol supplementation on bone health in HLS and ambulatory (AMB) rats.

Mature (age 6 months) and old (32 months) Fischer Brown Norway male rats were randomly assigned ( $n=7 /$ group) to HLS or kept ambulatory (AMB) for 14 days and received either $1 \mathrm{ml}$ of trans- resveratrol at a dose of 12.5

$\mathrm{mg} \cdot \mathrm{kg} \mathrm{bw}{ }^{-1} \cdot \mathrm{d}^{-1}$ or deionized water administered by oral gavage. After 14 days, both femurs and tibiae were collected. Bone mineralization was measured by dual energy x-ray absorptiometry (DEXA). Bone calcium (Ca) and phosphorus (P) were determined by inductively coupled plasma spectrophotometry. Bone architecture was determined using micro-computed tomography ( $\mu \mathrm{CT})$. Oxidation was determined by measuring plasma thiobarbituric acid reactive substances (TBARS) by enzyme immunoassay (EIA). Inflammation was determined by measuring $\mathrm{C}$-reactive protein (CRP) by ELIZA.

Results showed that aging increased plasma CRP and reduced trabecular bone $(P<0.001)$. In old AMB rats, resveratrol supplementation increased trabecular thickness $(P=0.018)$, but decreased tibia bone mineral area $(P=0.031)$ and bone mineral content $(P=0.034)$. In old HLS rats, resveratrol supplementation increased trabecular bone $(P<0.001)$ and reduced oxidation indicated by decreased plasma TBARS $(P<0.05)$ compared to rats not provided resveratrol. In mature HLS rats resveratrol supplementation reduced bone $\mathrm{Ca}$ $(P=0.018)$ and $\mathrm{P}(P=0.024)$ content. TBARS were increased compared to rats provided no resveratrol. In conclusion resveratrol supplementation attenuated trabecular loss but was not effective at attenuating bone mineral loss associated with aging. In mature HLS rats resveratrol supplementation increased plasma oxidation and reduced bone $\mathrm{Ca}$ and $\mathrm{P}$ content. Therefore, resveratrol is not recommended as a treatment for age-related bone loss. 


\section{ACKNOWLEDGEMENTS}

This work would never have been possible without my mentor, Dr. Janet Tou. Above anyone else, I would like to thank her for her guidance, support, and dedication. The magnitude of education she has provided me is of immeasurable proportions. I would also like to thank Dr. Cindy Fitch and Dr. Susan Partington for their willingness to serve on my committee and for their guidance and support. Gratitude is owed to my colleagues in the laboratory Joseph Gigliotti, Stephanie Altman, and Robin Lukas for their help with this project. Collaborative support from the Exercise Physiology department is gratefully acknowledged.

I would also like to thank my fiancé, Ken, for putting up with me over the past two grueling years. I am privileged to have such a patient and supportive companion. I'd like to thank my best friend and brother, John for his neverending encouragement and understanding. Lastly, I would like to thank my parents for instilling in me the endurance to prosper and the self-esteem to take pride in my accomplishments. 


\section{TABLE OF CONTENTS}

\section{Page}

ABSTRACT

ACKNOWLEDGEMENTS

TABLE OF CONTENTS iv

LIST OF TABLES vii

LIST OF FIGURES Ix

LIST OF ABBREVIATIONS $\quad$ X

1.0. INTRODUCTION 1

2.0. STUDY OBJECTIVES 4

3.0. LITERATURE REVIEW 5

3.1. Osteoporosis 5

3.2. Bone Biology 6

3.3. Bone Turnover $\quad 7$

3.4. Bone Biomechanics 9

3.5. Inflammation and Bone 11

3.6. Oxidative Stress and Bone 12

3.7. Antioxidants and/or Anti-inflammatory Compounds in the

Prevention of Bone Loss 13

3.8. Resveratrol 15

3.9. Mechanical Unloading of Bone 18

4.0. MATERIALS AND METHODS 20

4.1. Animal Feeding Study 20

4.2. Bone Morphometry 22 
4.4. Bone Mineral Density and Content 24

4.5. Bone Ash, Calcium and Phosphorus 25

4.6. Plasma Alkaline Phosphatase 26

4.7. Plasma Calcium and Phosphorus 26

4.8. Oxidative Stress 26

4.9. Plasma C-reactive Protein 27

4.10. Statistical Analysis 28

5.0. RESULTS 29

5.1. Final Body Mass in AMB male rats 29

5.2. Bone Morphometry in AMB male rats 29

5.3. Bone Mineralization in AMB male rats 29

5.4. Bone Architecture in AMB male rats 31

5.5. Bone Biomechanics in AMB male rats 31

5.6. Plasma Clinical Markers in AMB male rats 32

5.7. Final Body Mass in HLS male rats 38

5.8. Bone Morphometry in HLS male rats 38

5.9. Bone Mineralization in HLS male rats 38

5.10. Bone Architecture in HLS male rats 39

5.11. Bone Biomechanics in HLS male rats 39

5.12. Plasma Clinical Markers in HLS male rats 40 
6.0. DISCUSSION

7.0. SUMMARY AND CONCLUSION

8.0. REFERENCES

51 


\section{LIST OF TABLES}

Table 1. Bone morphometry of old and mature ambulatory male rats provided resveratrol or no resveratrol

Table 2. Femur and tibia bone mineral area, density, and content in mature and old ambulatory male rats provided resveratrol or no resveratrol

Table 3. Femur and tibia trabecular bone architecture in mature and old ambulatory male rats provided resveratrol or no resveratrol

Table 4. Biomechanical measurements of bone strength in mature and old ambulatory male rats provided resveratrol or no resveratrol

Table 5. Plasma measurements of bone formation, inflammation, and oxidative stress in mature and old ambulatory male rats provided resveratrol or no resveratrol

Table 6. Bone morphometry in old and mature hindlimb suspended male rats provided resveratrol or no resveratrol

Table 7. Femur and tibia bone mineral area, density, and content in old and mature hindlimb suspended male rats provided resveratrol or no resveratrol

Table 8. Femur and tibia trabecular bone architecture in old and mature hindlimb suspended male rats provided resveratrol or no resveratrol

Table 9. Biomechanical measurements of bone strength in old and mature hindlimb suspended male rats provided resveratrol or no resveratrol supplementation 
Table 10. Plasma measurements of bone formation, inflammation, and oxidative stress in mature and old hindlimb suspended male rats provided resveratrol or no resveratrol supplementation. 


\section{LIST OF FIGURES}

$\begin{array}{ll}\text { Figure 1. Biology of bone structure } & 7\end{array}$

$\begin{array}{lr}\text { Figure 2. Bone Turnover } & 9\end{array}$

Figure 3. A force-displacement curve resulting from a biomechanical test of a $\begin{array}{ll}\text { bone specimen } & 10\end{array}$

$\begin{array}{ll}\text { Figure 4. Resveratrol } & 17\end{array}$

Figure 5. Hindlimb Suspension Apparatus 19

Figure 6. Final Body Mass of mature and old ambulatory rats provided resveratrol

or no resveratrol 32

Figure 7. Final Body Mass of mature and old hindlimb suspended rats provided resveratrol or no resveratrol 


\section{LIST OF ABBREVIATIONS}

AMB

PG

BMD

HLS

COX

ALP

CRP

$\mathrm{Ca}$

DEXA

$\mathrm{BV} / \mathrm{TV}$

CME

MC

MR

$\mathrm{OC}$

OR

MHC

MHR

$\mathrm{OHC}$

OHR

UBS

BMA

BMC
Ambulatory

Prostaglandin

Bone Mineral Density

Hindlimb Suspension

Cycloxygenase

Alkaline Phosphatase

C-Reactive Protein

Calcium

Dual Energy X-ray Absorptiometry

Bone Volume normalized to Tissue Volume

Carboxymethylcellulose

Mature Control rats

Mature Resveratrol rats

Old Control rats

Old Resveratrol rats

Mature HLS Control rats

Mature HLS Resveratrol rats

Old HLS Control rats

Old HLS Resveratrol rats

Ultimate Bending Stress

Bone Mineral Area

Bone Mineral Content 
$\mu \mathrm{CT}$

$\mathrm{TbN}$

$\mathrm{TbTh}$

$\mathrm{TbSp}$

SMI

Connectivity

$\mathrm{P}$

ddH2O

ALP

MDA

TBARS
Micro Computed Tomography

Trabecular Number

Trabecular Thickness

Trabecular Separation

Structure Model Index

Connectivity Density

Phosphorous

Deionized Distilled Water

Alkaline Phosphatase

Malondialdehyde

Thiobarbituric Acid Reactive Substances 


\subsection{INTRODUCTION}

Polyphenols are compounds produced by plants to protect against insects, microbes, and disease. These compounds have been used in pharmaceuticals dating back to ancient times. Currently, a polyphenol of interest is resveratrol, a trans-3, 4, 4'-trihydroxystilbene structure. Resveratrol is found in various foods such as blueberries, peanuts, and mulberries (Vidavalur et al., 2006), but is particularly rich in the skin of red grapes. The popularity of resveratrol over the past two decades is partially due to the "French paradox." In the French population prevalence of heart disease is low despite high consumption of saturated fats. It was proposed that this reduction in heart disease was due to an increased intake of red wine (Kopp, 1998). This led to research regarding resveratrol as the constituent of red wine responsible for health benefits.

The health benefits of resveratrol have been attributed to its antioxidant and anti-inflammatory properties. Resveratrol has been shown to reduce oxygenderived free radicals in vitro (Pervaiz, 2003). In addition, in vitro studies have shown that resveratrol reduced pro-inflammatory eicosanoids, indicating antiinflammatory properties (Martinez and Moreno, 2000). Due to antioxidant and/or anti-inflammatory properties, resveratrol has been studied for its roles in reducing the effects of aging. Bone loss leading to osteoporosis is often associated with aging. Research on resveratrol as a dietary supplement for reducing bone loss has been increasing; however, most studies have been in vitro. Few studies in vivo have investigated the role of resveratrol in preventing bone loss associated with aging. 
Rats are often used as an animal model to study bone loss in humans. Male osteoporosis is typically an age-related disorder, developing after the age of 60 (Raisz, 2005). Therefore, the use of an appropriate aged male rat model is important in order to investigate age-related bone loss in males. Bone growth begins to slow in male rats at maturity (age six months) (Wang et al., 2001). At age nine months, male rats begin to lose bone similar to men age 60 or older (Jee and Ma, 1999). Therefore, the use of age six-month-old and older rats provide an appropriate animal model of bone loss.

In addition to age-related bone loss, the elderly experience declining activity levels and increased incidence of bed rest. This results in reduced mechanical load which is associated with lower bone mineral density (BMD) (Magnus et al., 2008). In rats, hindlimb suspension (HLS) has been used to simulate the effects of inactivity or bed rest. HLS involves suspending rats from the tail to unload weight from the hindlimbs while allowing the forelimbs to move freely (Vico et al., 1995).

More than 40 million Americans over the age of 50 have either reduced BMD or osteoporosis (Gronholz, 2008). In the absence of a cure for bone loss leading to osteoporosis, emphasis is placed on prevention. Oxidative stress has been associated with reduced BMD (Basu et al., 2001). Antioxidants such as vitamin $\mathrm{E}$ have been reported to be bone protective in young ( 3 month old) nicotine withdrawn rats (Hermizi and Faizah, 2009), and mature (8.5 month old) hindlimb suspended rats (Smith et al., 2005). In these studies, vitamin E was shown to protect bone weight, mineralization, and strength. Vitamin E may also 
affect bone by inhibiting the enzyme cycloxygenase 2 (COX-2) and decreasing the prostaglandin (PG), $\mathrm{PGE}_{2}$ (Smith et al., 2005). In vitro, $\mathrm{PGE}_{2}$ increased bone resorption by promoting osteoclast formation (Klein and Raisz, 1970). Studies in mice and humans also provided evidence that $\mathrm{PGE}_{2}$ enhances bone resorption (Norrdin et al., 1990). Therefore, resveratrol may provide a dietary supplement for reducing bone loss due to its antioxidant and anti-inflammatory properties. The objective of the proposed study is to determine the effects of resveratrol supplementation on bone mineralization and strength in ambulatory or hindlimb suspended mature and old male rats. To our knowledge the proposed study is the first to investigate the effects of resveratrol supplementation of aging male rats on bone. The study results are expected to contribute knowledge towards developing dietary recommendations to reduce age-related bone loss leading to osteoporosis. 


\subsection{STUDY OBJECTIVES}

\section{Hypothesis}

Resveratrol supplementation will positively affect bone mass, bone mineral content, and bone mineral density leading to increased bone strength when consumed by mature and old, ambulatory and HLS rats

To test this hypothesis, the study objectives were:

Objective 1: To determine the effects of resveratrol supplementation on bone mass and bone strength in mature and old male rats.

Objective 2: To determine the effects of resveratrol supplementation and hindlimb suspension on bone mass and bone strength in mature and old male rats.

Objective 3: To determine potential mechanisms of actions of resveratrol on bone. 


\subsection{LITERATURE REVIEW}

\subsection{Osteoporosis}

Osteoporosis is a condition that is characterized by a decrease in bone mass due to decreased bone mineral density (BMD) and bone matrix (Kiebzak et al., 2002). Reduced BMD and bone architecture results in bone fracture with minimal trauma. Bone fractures usually occur at the hip, specifically the femoral neck. After sustaining a hip fracture, only $15 \%$ of patients are able to return to unassisted ambulation within six months, and almost one in four hip-fracture patients will die within a year (Reginster and Burlet, 2006). More than 40 million Americans over the age of 50 have either osteoporosis or low BMD. Approximately13 million are males (Gronholz, 2008). However, most studies of osteoporosis have focused on post-menopausal women. Only $4.5 \%$ of men with hip fractures receive treatment for osteoporosis compared to $27 \%$ of women (Gruntmanis, 2007). Therefore, it is also important to study osteoporosis in males.

In the absence of a cure for bone loss leading to osteoporosis, it is important to identify modifiable factors such as diet and exercise to prevent bone loss. Nutrition and exercises that increase bone formation and reduce bone resorption may reduce the risk of osteoporosis. The next sections discuss bone biology and bone turnover. 


\subsection{Bone Biology}

The two basic types of bone are cortical (compact) and trabecular (spongy) bone (Figure 1). Cortical bone provides support for the body and storage of minerals. Cortical bone makes up the shaft of the long bones and constitutes approximately $85 \%$ of the total bone in the body. Trabecular or cancellous bone has a sponge-like structure that provides a large surface area for mineral storage. Cancellous bone makes up the internal parts of the bone and typically occurs at the ends of the long bones. Cancellous bone also provides the sites for bone forming cells.

During aging, cortical and cancellous bone changes differ with loss of trabecular bone occurring earlier (Mundy, 1993). Therefore, it is important to measure loss of the different types bone when studying osteoporosis. Cortical mineralization can be determined using dual energy X-ray absorptiometry (DEXA). Measurements include bone mineral area (BMA), bone mineral content (BMC) and bone mineral density (BMD). BMA represents the area of bone occupied by minerals. BMC represents the mass of the bone, and BMD is a measurement of the bone mass per $\mathrm{cm}^{2}$ (Mazess et al., 1990.)

Trabecular architecture can be determined using micro-computed tomography $(\mu \mathrm{CT})$. Measurements of trabecular architecture include bone volume to total tissue volume ratio (BV/TV), trabecular number $(\mathrm{TbN})$, trabecular separation (TbSp), trabecular thickness (TbTh), Structure Model Index (SMI), and connectivity density $(\mathrm{CONN})$. BV/TV represents the fraction of bone in the sample. $\mathrm{TbN}$ is the number of trabulae per mm bone. TbSp corresponds to the 
mean size of the intertrabecular spaces. TbTh represents the mean diameter of the trabeculae. SMI characterizes the type of structure of the sample (rod-like, platelike or mixed structures), and CONN is a quantified measurement of elasticity (Peyrin et al., 1998). Loss of trabecular and cortical bone is linked to increased bone turnover.

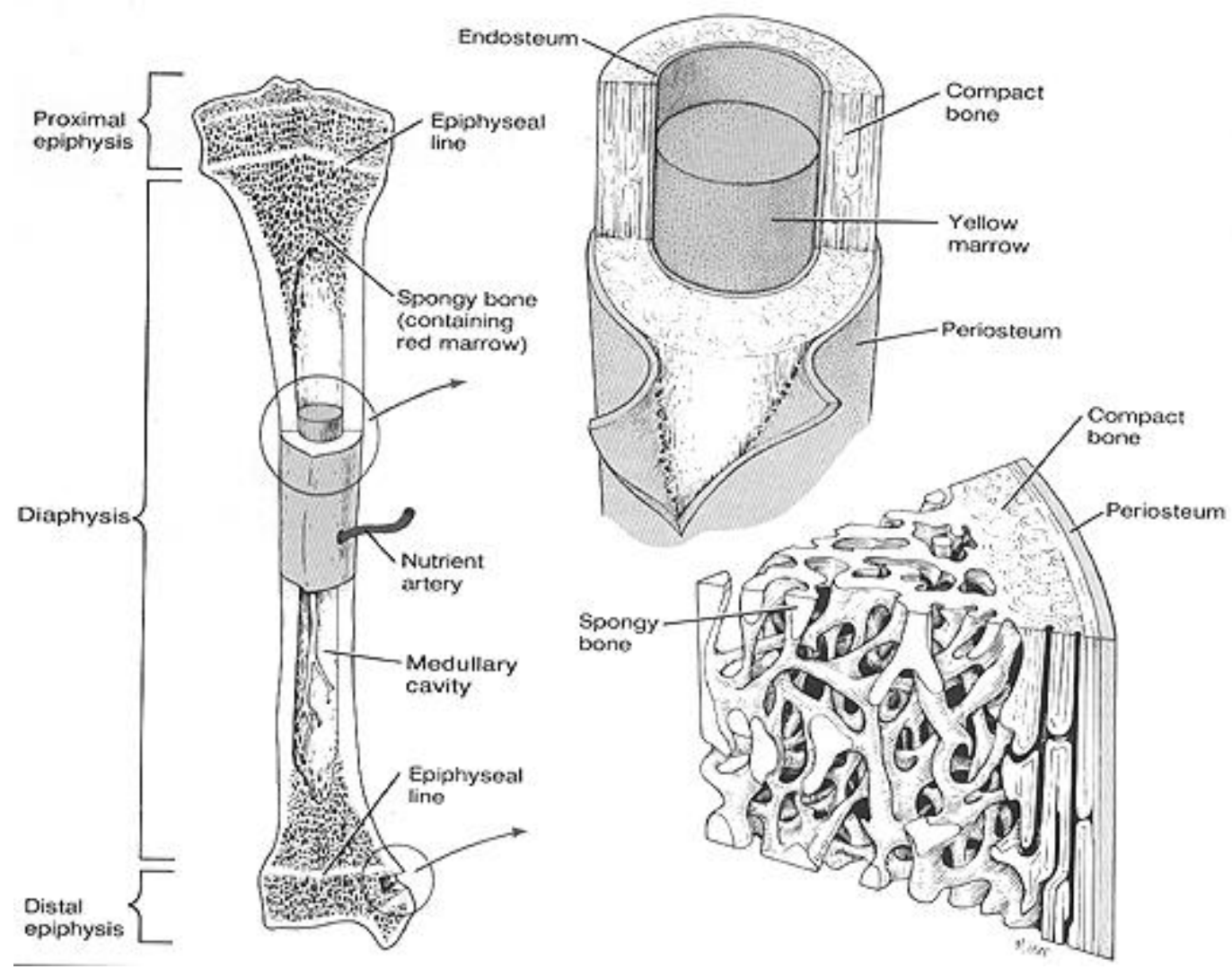

Figure 1. Biology of bone structure, adapted from Spence A, 1990.

\subsection{Bone Turnover}

Bone turnover is a process by which old bone is broken down (resorption) and new bone is formed (deposition). The cells responsible for bone deposition are osteoblasts; whereas, the cells responsible for resorption are osteoclasts. As 
illustrated in Figure 2, remodeling starts with the activation of hematopoietic precursors to become osteoclasts that promote bone resorption. Activation of osteoclasts can be initiated by inflammatory cells. Following bone resorption, osteoclasts signal osteoblasts to begin forming bone matrix and to deposit minerals. Alkaline phosphatase (ALP) is associated with bone matrix synthesis prior to mineralization (Cao et al., 2009). Therefore, plasma ALP has been used as an indicator of bone formation.

Bone is constantly being remodeled throughout adult life resulting in the removal of old bone (resorption) and replacement by new bone (deposition). In general, the processes of bone resorption and formation are "coupled" so that there is no net change in bone mass. During aging bone resorption exceeds bone formation leading to a net increase in bone loss. In humans, bone mass and strength are obtained from approximately age 15 to the mid-thirties (Gruntmanis, 2007). Unlike in humans, in rats the epiphyses do not fuse resulting in bone growth up to old age (Dawson, 1925). To study age-related bone loss, the use of appropriate aged male rat model is important. Wang et al. (2001) reported that proximal tibia and femoral neck bone mineral accrual slowed at age six months, and bone loss began at age nine months in male Sprague-Dawley rats. Therefore, in rat models it is important to include bone morphometry measurements of length, width, depth, and weight even in aging rats (Jee and Ma, 1999). Loss of bone mineral and matrix results in reduced bone strength and in turn, increased risk of bone fracture. The next section discusses bone biomechanical strength measurements. 
Figure 2. Bone Turnover

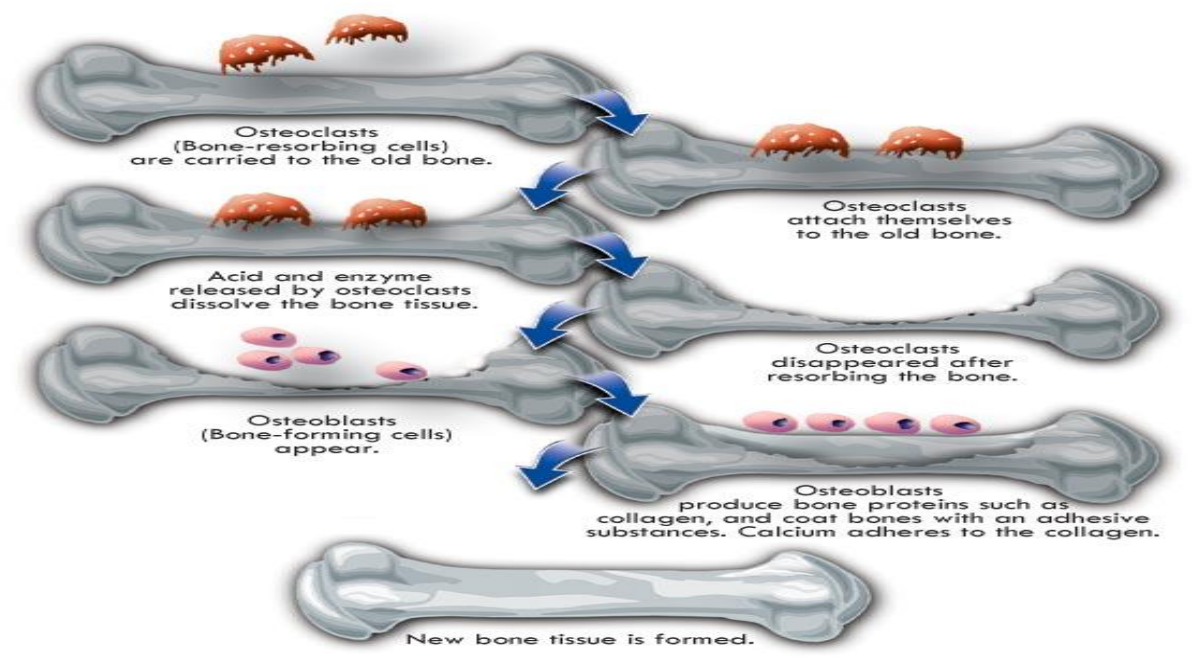

\subsection{Bone Biomechanics}

Biomechanical properties can determine bone susceptibility to fractures.

Bone fractures occur as a result of different etiologies; therefore, several different biomechanical measurements define bone fragility. Biomechanical indices of bone fragility include: strength, brittleness, and work to failure and stiffness which is also used to assess mechanical integrity of the bone (Turner, 2002). These indices are derived from a biomechanical test in which force is applied to a bone until it breaks. A force-displacement curve (Figure 3 ) is generated from the biomechanical test. Bone strength (ultimate force) is defined as the height of the curve. Work to failure is defined as the area under the curve and brittleness is estimated from the reciprocal of the curve (Turner, 2002). Ultimate bending stress and Young's modulus are also biomechanical measurements used to 
determine bone properties. Ultimate bending stress is a normalized calculated force that takes into account the size of the bone, and Young's modulus is normalized stiffness that takes into account bone size (Yuan and Kitts, 1992).

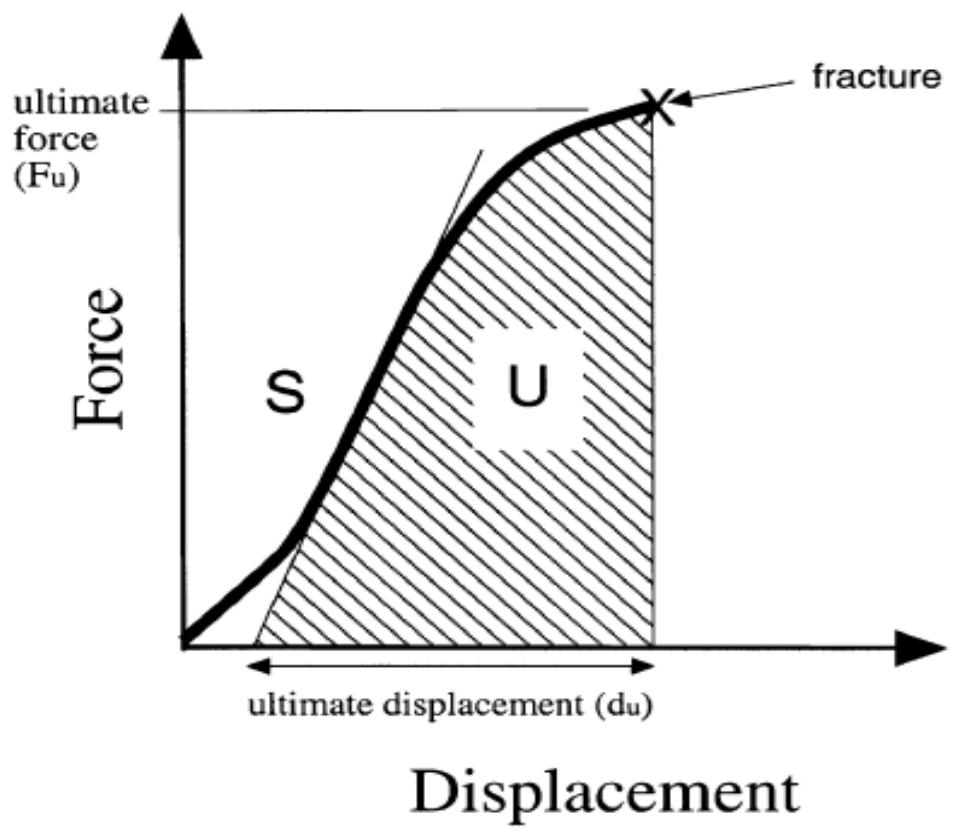

Figure 3. A force-displacement curve resulting from a biomechanical test of a bone specimen. The height of curve represents ultimate force (Fu), area under the curve (U) represents work to failure energy, the slope of the curve is the stiffness (S) and the width of the curve is the ultimate displacement (du). (Turner, 2002)

Aging is associated with a number of conditions with the potential to accelerate bone loss such as: chronic inflammation, increased free radicals, and reduced physical activity. The next sections examine the effect of these factors on bone. 


\subsection{Inflammation and Bone}

Inflammation is an immune response to injury or infection. C-reactive protein (CRP) is a substance secreted by the liver during acute inflammation. Higher serum levels of CRP are associated with lower BMD in older adults. Ding et al. (2007) reported that high-sensitivity (hs)-CRP was inversely associated with total body BMD in men and women (age 52-78). Additionally, hs-CRP was positivity associated with urinary pyridinoline, a marker for bone resorption.

Inflammatory compounds also include eicosanoids derived from fatty acids. Cyclooxygenases (COX) enzymes mediate the production of a class of eicosanoids called prostaglandins (PGs). Prostaglandin $\mathrm{E}_{2}\left(\mathrm{PGE}_{2}\right)$ derived from conversion of the fatty acid arachidonic acid (20:4 n-6) by COX-2, has been shown to stimulate both osteoclast and osteoblast formation (Klein and Raisz, 1970). $\mathrm{PGE}_{2}$ released from osteoblasts promotes the formation of osteoclasts for bone remodeling (Norrdin et al., 1990). Chronic overproduction of $\mathrm{PGE}_{2}$ results in increased bone resorption (Klein and Raisz, 1970). COX-1 and COX-2 inhibitors such as non-steroidal anti-inflammatory drugs (NSAIDS) have been shown to decrease inflammation markers as well as reduce bone resorption by inhibiting osteoclast formation in vitro (Raisz, 2001). In addition, epidemiological studies show that patients who take aspirin have slightly higher $(P<0.05)$ bone mass at the femoral neck and lumbar spine compared to agematched patients not taking aspirin (Bauer et al., 1996).

Other inflammatory mediators associated with bone metabolism are cytokines. Cytokines have been shown to stimulate osteoclast formation in vitro 
and in vivo (Manolagas and Jilka, 1995), and to inhibit osteoblast differentiation in vitro (Gilbert et al., 2000). In addition, higher levels of serum CRP and cytokines in elderly (age 70-79) men and women are associated with increased risk of bone fracture (Cauley et al., 2007).

During chronic states of inflammation, increased expression of inflammatory cytokines recurrently activates macrophages which in turn produce more inflammatory cytokines (Feghali and Wright, 1997). Perpetual cytokine articulation amplifies osteoclast formation and bone resorption (Mundy, 1993). In addition to inflammation, aging also increases generation of free radicals. Recent studies have suggested a role of increased free radicals in bone loss.

\subsection{Oxidative Stress and Bone}

Free radicals are molecules that have an unpaired electron. As a result, free radicals are highly reactive and may cause damage (oxidation). Excessive production of free radicals with insufficient antioxidants results in oxidative stress. Oxidative stress has been linked with aging and increased risk of degenerative diseases including osteoporosis (Basu et al., 2001).

Cell cultures of mouse frontal and parietal bones and of rat radii and ulnae were shown to release calcium $(\mathrm{Ca})$ into media when exposed to superoxide anions $\left(\mathrm{O}^{2-}\right)$, hydrogen peroxide $\left(\mathrm{H}_{2} \mathrm{O}_{2}\right)$, or hydroxyl radicals $(\mathrm{OH} \cdot)$. The authors suggested that release of $\mathrm{Ca}$ indicated increased bone resorption. The antioxidant enzyme superoxide dismutase (SOD) was added at a dose of $6 \mu \mathrm{M}$ to bone cell 
culture. Bone resorption measured by the percentage of total Ca released into media was inhibited by SOD (Garret et al., 1990).

In a study using 48 women and 53 men (age 22-85 years) the biomarker of oxidation, urinary 8 -iso-PGF2 $\alpha$ was measured to determine the association of oxidation to BMD at the lumbar spine, femoral hip and total body. Higher 8-isoPGF2 $\alpha$ levels were associated with lower BMD, specifically at the lumbar spine and total body, indicating a negative relationship between oxidation and BMD (Basu et al., 2001). The importance of antioxidants in reducing risk of osteoporosis was demonstrated in a study showing that men and women with osteoporosis $(\mathrm{n}=50)$ had lower $(P<0.05)$ activity of the endogenous antioxidant glutathione peroxidase (GPx) than subjects without osteoporosis $(n=44)$. In addition, higher GPx was positively correlated (r=0.31, $P<0.001)$ to heel BMD measured by dual energy x-ray absorptiometry (DEXA) (Sanchez-Rodriguez et al., 2007). Chronic inflammation and oxidative stress have been shown to be detrimental to bone. Therefore, it is important to discuss strategies for reducing inflammation and/or oxidative stress to prevent bone loss.

\subsection{Antioxidants and/or Anti-inflammatory Compounds in the Prevention of Bone Loss}

In a human study, postmenopausal women age 50-98 years who were provided with vitamin $\mathrm{C}$ at supplemental doses of 100 to $5,000 \mathrm{mg} / \mathrm{d}$ for 12 years had higher $(P=0.02) \mathrm{BMD}$ at the femoral neck compared to women not receiving vitamin C supplements (Morton et al., 2001). Osteoblast cells grown in media 
containing $50 \mu \mathrm{g} / \mathrm{ml}$ of the antioxidant vitamin, ascorbic acid (vitamin C) for 2448 hours increased osteoblast differentiation and ALP mRNA expression. The results suggested that antioxidants promote bone health by promoting osteoblastic deposition (Franceschi et al., 1994).

Another antioxidant vitamin, tocopherol (vitamin E) also has antiinflammatory properties. In an animal study, young (3 month old) nicotine withdrawn male Sprague-Dawley rats provided vitamin E supplementation (60 $\mathrm{mg} / \mathrm{kg}$ body weight/day) for 8 weeks had increased bone mass and mineralization. Increased bone mineralization was indicated by histological measurements of increased bone volume normalized to tissue volume (BV/TV), mineral apposition rate (MAR), and bone formation rate normalized to bone volume (BFR/BV) (Hermizi and Faizah, 2009). Vitamin E may decrease bone resorption by inhibiting the enzyme COX-2 and decreasing serum $\mathrm{PGE}_{2}$ (Smith et al., 2005).

Numerous polyphenols existing in fruits and vegetables have been shown to have both anti-inflammatory and antioxidant properties (Habauzit and Horcajada, 2008). Epigallocatechin-3-gallate (EGCG), a phenolic compound in green tea, has been shown in vitro to inhibit osteoclast formation and activity by reducing free radical production (Habauzit and Horcaja, 2008). Flavonoids (i.e. quercetin and kaempferol) found in red apples have been shown to inhibit COX-2 and to suppress osteoclast differentiation and bone resorption in vitro (Wattel et al., 2003). Dried plum polyphenols have been shown to decrease COX-2 and cytokine expression (Bu et al., 2008). Osteoblasts grown in media containing 10, 20 , or $30 \mu \mathrm{g} / \mathrm{mL}$ dried plum polyphenols, chlorogenic acid and caffeic acid 
showed decreased osteoclast differentiation and oxidative stress under normal and inflammatory states. Resveratrol, a polyphenolic compound, may have beneficial health effects due to antioxidant and anti-inflammatory properties. However, few studies have investigated the effect of resveratrol on bone, particularly in vivo.

\subsection{Resveratrol}

Resveratrol is a 3, 4, 4'-trihydroxystilbene structure consisting of two phenol rings linked by a styrene double bond. This double bond facilitates the formation of two isomeric forms. The trans structure is more abundant, but it transforms into the cis form when exposed to ultraviolet light (Figure 4). In addition being classified as a polyphenol, resveratrol may also be categorized as a phytosterol, phytoestrogen, and phytoalexin.

Resveratrol is produced by plants such as red grapes, eucalyptus, spruce trees, certain species of lilies, peanuts, blueberries, and mulberries upon exposure to fungal infection, insects, or microbes. Resveratrol is produced as a defense mechanism against external toxins and therefore, is most abundant in the outer layer of the plants (Pervaiz, 2003).

In vivo studies reported $38 \%$ bioavailability when resveratrol was orally administered to male Sprague-Dawley rats (Marier et al., 2002). In humans, approximately $70 \%$ of orally administered resveratrol is absorbed (Goswami and Das, 2009). Following absorption in the small intestines, resveratrol enters the hepatic portal vein and is glucuronidated in the liver. Both trans- and cisresveratrol undergo enterohepatic recirculation and then enter the bloodstream 
after a period of 4 to 8 hours (Marier et al., 2002). In the circulation resveratrol binds to lipoproteins and albumin, and its cellular uptake is carrier mediated (Goswami and Das, 2009). Over 99\% of absorbed resveratrol is distributed to tissues. Less than $0.15 \%$ of absorbed resveratrol is excreted in the urine (Marier et al., 2002). In the body, resveratrol has been reported to have various beneficial effects.

Resveratrol has been widely investigated as an antioxidant (Leonard et al., 2003). In addition, resveratrol is capable of reducing inflammation (Pervaiz, 2003). As an anti-inflammatory compound, resveratrol's main mode of action is the suppression of COX enzymes which mediate the production of a class of eicosanoids called prostaglandins (PGs). Resveratrol supplementation at doses of 0.10-10 $\mu \mathrm{M}$ has been shown to decrease the production of $\mathrm{PGE}_{2}$ by osteoblasts in vitro by approximately 30\% (Mizutani et al., 1998). Since $\mathrm{PGE}_{2}$ released from osteoblasts promotes the formation of osteoclasts, resveratrol may reduce osteoclast resorption of bone by reducing $\mathrm{PGE}_{2}$ production.

In cell culture studies, resveratrol has been shown to influence osteoblasts and osteoclasts. Resveratrol supplementation at doses of $25-100 \mu \mathrm{M}$ has been shown to decrease osteoclast differentiation (Boissy et al., 2005) and to promote osteoblast differentiation at doses of 0.10-100 $\mu \mathrm{M}$ (Dai et al., 2007).

Most research investigating the effect of resveratrol supplementation on bone has been conducted in vitro. Few studies have investigated the effect of resveratrol supplementation on bone health in vivo. Young (age 3 months) ovariectomized Sprague-Dawley rats provided resveratrol at a dose of $45 \mathrm{mg} / \mathrm{kg}$ 
body weight/day for 13 weeks resulted in protection against ovariectomy induced BMD loss at the lumbar spine and femur (Lin et al., 2005). Low dose resveratrol supplementation $(0.7 \mathrm{mg} / \mathrm{kg}$ body weight/day) in young ovariectomized SpragueDawley rats for 12 weeks resulted in increased BMD and bone Ca content (Liu, et al., 2005). In addition, resveratrol supplementation in mature (aged 5 months) ovariectomized spontaneously hypertensive rats at a dose of $0.5 \mathrm{mg} / \mathrm{kg}$ body weight/day for just 3 weeks reduced ovariectomy induced loss of femur strength without affecting calcium and phosphorus content (Mizutani et al., 2000). To our knowledge no studies have investigated the potential effect of dietary resveratrol supplementation on age-related bone loss in male rats.

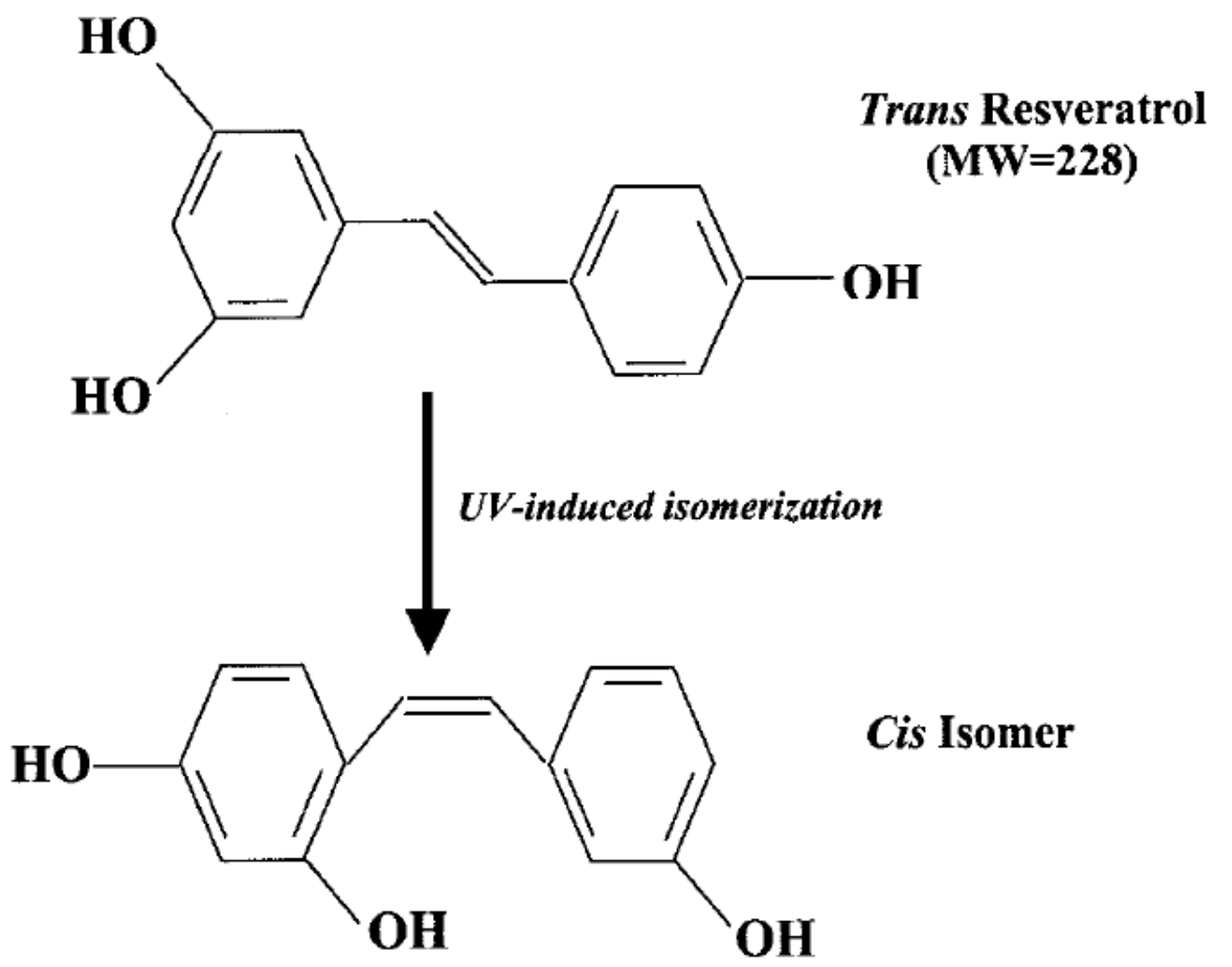

Figure 4. Resveratrol 


\subsection{Mechanical Unloading of Bone}

It is well-established that mechanical unloading such as decreased physical activity and bed rest accelerates bone loss due to increased resorption (LeBlanc et al., 2005). Exercise has been shown to help protect against bone loss. However, individuals over the age of 50 are a population already at high risk for bone loss and are also the most sedentary adults (King et al., 1998). During their lifetime, half of all women and one-third of all men will suffer a bone fracture (Magnus et al., 2008). Only $15 \%$ of hip fracture patients are able to return to unassisted ambulation after 6 months (Reginster and Burlet, 2006). Furthermore, decreased activity in hip fracture patients increases subsequent bone fracture due to loss of skeletal integrity.

Hindlimb suspension (HLS) has been used in rats to model the effects of mechanical unloading on bones. In HLS, the rat is suspended from its tail to mechanically unload the hindlimbs while allowing the forelimbs to move freely (Figure 5). HLS for two weeks has been shown to promote bone loss.

Administration of vitamin $\mathrm{E}$ to mature ( 8.5 month old) hindlimb suspended male Sprague-Dawley rats has been shown be bone protective. Vitamin E supplementation at a dose of $500 \mathrm{IU} / \mathrm{kg}$ diet for 9 weeks increased bone mass indicated by increased bone surface normalized to tissue volume (BS/TV) by acting as an antioxidant.

Resveratrol has antioxidant properties, but to our knowledge no studies have investigated the effect of dietary resveratrol supplementation on bone in HLS rats. Few studies have investigated the role of resveratrol in improving bone 
loss associated with aging, and to our knowledge no studies have investigated effects of resveratrol on bones in male rats.

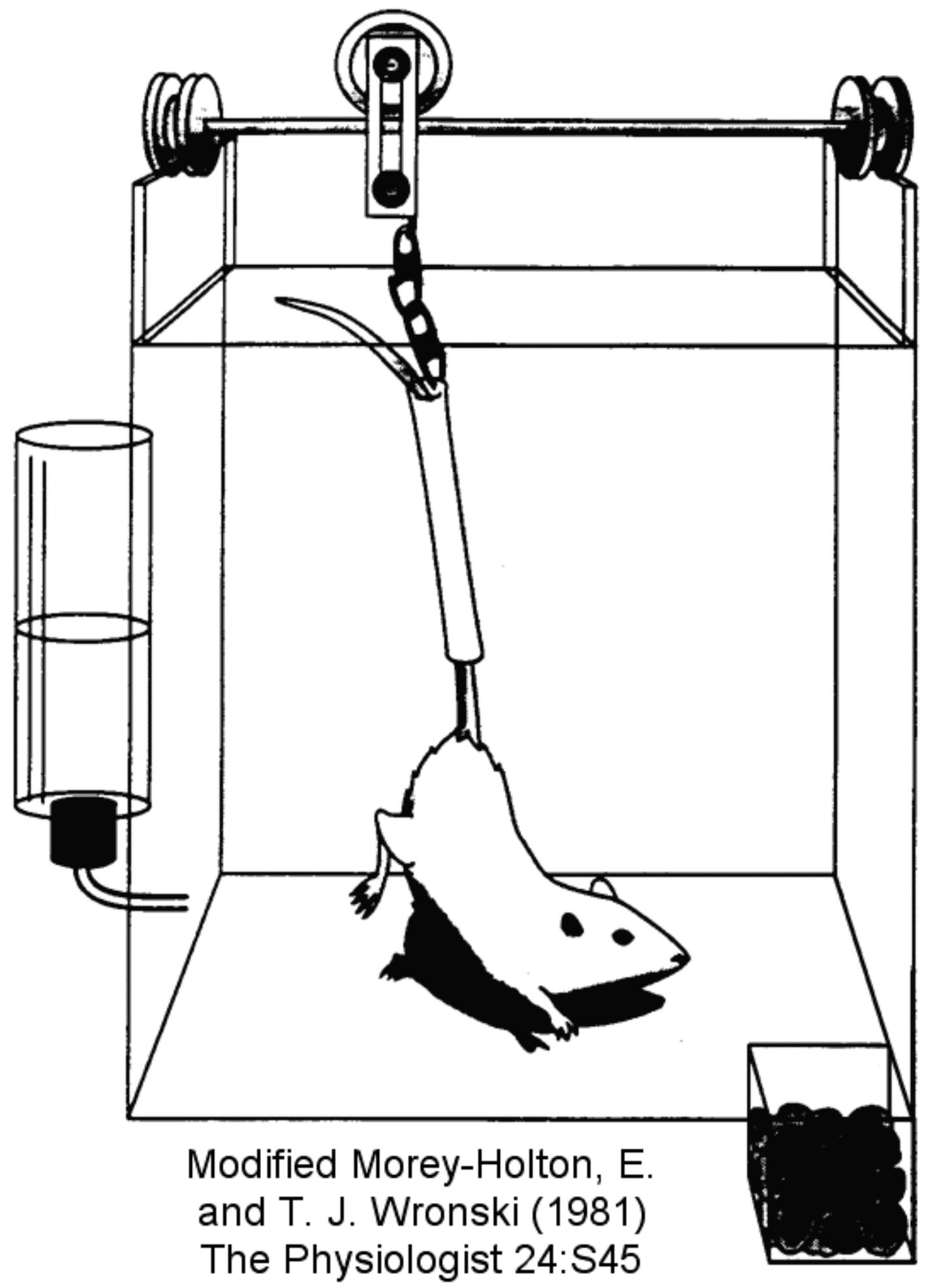

Figure 5. Hindlimb Suspension Apparatus 


\subsection{MATERIALS AND METHODS}

\subsection{Animal Feeding Study}

All animal procedures were approved by the Animal Care and Use Committee at West Virginia University and were conducted in accordance with the guidelines set forth by the Institute of Laboratory Animal Resources Commission on Life Sciences for the Care and Use of Laboratory Animals (1996). Upon arrival in the animal care facilities, mature (6 months) and old (32 months) male Fischer Brown Norway rats $(n=56)$ were individually caged and kept in rooms maintained at $22+2^{\circ} \mathrm{C}$ with a $12: 12 \mathrm{~h}$ light/dark cycle $(6: 00 \mathrm{am}$ light on/6:00 pm lights off). Rats were provided with water and standard rat chow (Formlab 5008, PMI Feeds Inc, Richmond, IN) ad libitum throughout the $14 \mathrm{~d}$ study.

In Study 1 the effect of resveratrol supplementation at different ages on bone was determined. Mature (6 months) and old (32 months) rats were acclimated for 7 days. Following 7 day acclimation, mature and old rats were randomly assigned ( $\mathrm{n}=7 /$ group) to receive $1 \mathrm{ml}$ of trans-resveratrol suspended in 1 milliliter of $0.1 \%$ carboxymethylcellulose (CME) or vehicle consisting of $1 \mathrm{ml}$ deionized water dissolved in $0.1 \% \mathrm{CME}$ (control). The treatment solutions were administered at a dose of $12.5 \mathrm{mg} \cdot \mathrm{kg} \mathrm{bw}^{-1} \cdot \mathrm{d}^{-1}$ by daily oral gavage for $14 \mathrm{~d}$. 
The treatment groups were:

1) Mature control rats (MC)

2) Mature resveratrol rats (MR)

3) Old control rats (OC)

4) Old resveratrol rats (OR)

In Study 2 mechanical unloading of bone was investigated because aging is often accompanied by reduced physical activity and bed rest. Mature (6 months) and old (32 months) male Fischer Brown Norway rats were hindlimb suspended (HLS) according to Morey-Holton and Globus (2002) as shown in Figure 3. The individually housed rat was suspended by its tail. This allowed unloading of weight from the hindlimbs while allowing free ambulation of the forelimbs. This provided rats with $360^{\circ}$ movement around the cage and free access to diet and water. Rats were HLS for $14 \mathrm{~d}$. HLS for $14 \mathrm{~d}$ is the minimal time shown to produce bone loss (Vico et al., 1995).

Similar to study 1 , following a $7 \mathrm{~d}$ acclimation, the mature and old HLS rats were randomly assigned ( $\mathrm{n}=7 /$ group) to receive $1 \mathrm{ml}$ of trans-resveratrol suspended in 1 milliliter of $0.1 \%$ CME or vehicle consisting of $1 \mathrm{ml}$ deionized water dissolved in $0.1 \% \mathrm{CME}$ (control). The treatment solutions were administered at a dose of $12.5 \mathrm{mg} / \mathrm{kg}$ body weight/d by daily oral gavage for $14 \mathrm{~d}$. 


\section{Treatment groups were:}

1) Mature hindlimb control rats (MHC)

2) Mature hindlimb resveratrol rats (MHR)

3) Old hindlimb control rats $(\mathrm{OHC})$

4) Old hindlimb resveratrol rats (OHR)

In Study 1 and 2, rats were euthanized after $14 \mathrm{~d}$ with a mixture of $5 \%$ isoflourane and $95 \%$ oxygen using a small animal anesthetic system (Isotec 5, Ohmeda) at the end of the $14 \mathrm{~d}$. The right and left femur and tibia were collected and stored at $-20^{\circ} \mathrm{C}$ until used for bone measurements. The femur and tibia were examined because Lafage-Proust et al. (1998) reported that in rats the femur was a slower maturing bone than the tibia and, therefore, more sensitive to unloading.

\subsection{Bone Morphometry}

The bones were brought to room temperature and carefully defleshed without damaging the periosteum. Each bone was individually wrapped in deionized distilled water-soaked gauze and stored at $-20^{\circ} \mathrm{C}$ until analysis. To determine bone morphometry, bones were brought to room temperature and weighed. Bones were weighed using an analytical balance (A-200DS, Fisher Scientific). Bone length, width, and depth were determined using a vernier caliper (Bel-Art Products, Pequannock, NJ). Length was measured from medial condyle to greater trochanter. Diameter was measured at mid-section of shaft from lateral to medial end i.e. diaphysis. 


\subsection{Bone Biomechanics}

Bone strength parameters were assessed using a TA.HDi Texture Analyzer (Texture Technologies Corp, NY) outfitted with a three-point bending apparatus. The right and left femora and tibiae were placed on supports and bent until broken by lowering a centrally placed blade at constant crosshead speed $(2 \mathrm{~mm} / \mathrm{s})$ and load cell of $250 \mathrm{~kg}$. A PC interfaced with the Texture Analyzer was used to collect data for determination of bone strength measurements of peak force, ultimate stiffness, ultimate bending stress (UBS), and Young's modulus as described by Yuan et al. (1992) The bone biomechanical forces were calculated as:

1) Peak force $(\mathrm{N})$ : the maximum force obtained during the bending procedure resulting in the initiation of the bone breaking

2) Ultimate stiffness (N/s): the slope of the time-force deformation curve

3) Ultimate bending stress (UBS, N/mm²): a normalized, calculated force that takes into consideration the size of the bone calculated as:

$\mathrm{UBS}=\quad 8 \times$ peak force $\times \mathrm{L} \times \mathrm{a}_{1}$

$$
\text { Л }\left(\left(a_{1}{ }^{3} a_{2}\right)-\left(b_{1}{ }^{3} b_{2}\right)\right)
$$

Where $\mathrm{L}$ is the distance between the supporting points $(10 \mathrm{~mm}) ; \mathrm{a}_{1}=$ the outer diameter in the direction of the load, $\mathrm{a}_{2}=$ the outer diameter at right angles to $a_{1}, b_{1}=$ the inner diameter in the load direction and $b_{2}=$ the inner diameter at right angles to $b_{1}$. 
4) Young's Modulus (YM, N/mm²): a normalized calculated stiffness that takes into consideration the size of the bone calculated as:

Young's Modulus $=\quad 4 \times \mathrm{L}^{3} \times$ ultimate stiffness (slope)

$$
3 \times Л\left(\left(a_{1}^{3} a_{2}\right)-\left(b_{1}^{3} b_{2}\right)\right)
$$

Where $\mathrm{L}=$ the distance between the two edges in the three-point bending $(10 \mathrm{~mm}), \mathrm{a}_{1}=$ the outer diameter in the direction of the load, $\mathrm{a}_{2}=$ the outer diameter at right angles to $\mathrm{a}_{1}, \mathrm{~b}_{1}=$ the inner diameter in the load direction and $b_{2}=$ the inner diameter at right angles to $b_{1}$.

\subsection{Bone Mineral Density and Content}

The left bones were packed on dry ice and shipped overnight to Oklahoma State University. Dual energy X-ray absorptiometry (DEXA) scans (Hologic QDR 4500-A Elite) were performed on excised tibial and femoral specimens placed in Millipore water. Bone mineral area (BMA), bone mineral content (BMC), and bone mineral density (BMD) were evaluated from all scans using the Regional High Resolution software package designed for studying isolated bone specimens (Hologic Waltham, MA).

To assess bone architecture, the femur and tibia were scanned using $\mu \mathrm{CT}$ (MicroCT40, SCANCO Medical, Switzerland). The distal femur metaphysis and proximal tibial metaphysis were scanned and 200 images $(\sim 16 \mu \mathrm{m} /$ slice or 3.2 $\mathrm{mm}$ ) were analyzed by semi-automatically placing contours beginning 25 slices $(400 \mu \mathrm{m})$ away from the growth plate and included only secondary spongiosa 
within the volume of interest (VOI). All scans were performed utilizing a $1024 \mathrm{x}$ 1024 matrix resulting in an isotropic voxel resolution of $22 \mu \mathrm{m}^{3}$. An integration time of 70 milliseconds per projection was used with a rotational step of 0.36 degrees resulting in total acquisition time of approximately 150 minutes/sample. The VOI was assessed for structural parameters including trabecular bone volume per unit of total volume (BV/TV), trabecular number $(\mathrm{TbN})$, trabecular thickness (TbTh), trabecular separation (TbSp), structure model index (SMI) and connectivity density (CONN).

\subsection{Bone Ash, Calcium, and Phosphorus}

The femur and the tibia were dried at $110^{\circ} \mathrm{C}$ for $24 \mathrm{~h}$ to determine dry weights. Total bone ash content of the femur and of the tibia was determined by ashing the dried bones at $600^{\circ} \mathrm{C}$ in a muffle furnace (model $19.2 \mathrm{~A}$, Fisher Scientific) for 24 hours. Total bone ash was determined by weighing the bone ash. To determine bone calcium $(\mathrm{Ca})$ and phosphorous $(\mathrm{P})$ content, ashed samples were dissolved in $2 \mathrm{~mL}$ of $70 \%$ nitric acid. The acidified samples were neutralized in $5 \mathrm{ml}$ deionized distilled water $\left(\mathrm{ddH}_{2} \mathrm{O}\right)$ and filtered through Whatman no. 1 paper. Samples were diluted to volume with $\mathrm{ddH}_{2} \mathrm{O}(500 \mathrm{~mL})$. Femur and tibia $\mathrm{Ca}$ and $\mathrm{P}$ concentrations were determined by inductively coupled plasma optical emission spectrophotometry (model P400, Perkin Elmer, Shelton, $\mathrm{CN})$. 


\subsection{Plasma Alkaline Phosphatase}

Plasma alkaline phosphatase (ALP) was measured as an indicator of osteoblast activity i.e. bone formation. ALP was determined by enzymatic reactions that produced a color changes using a vet 16 rotor Hemagen Analyst (Hemagen Diagnostics, Inc. Columbia, MD). The rotors were read using the Hemagen Analyst automated spectrophotometer (Hemagen Diagnostics, Inc. Columbia, MD).

\subsection{Plasma Calcium and Phosphorus}

Rats were euthanized with isoflurane and blood samples obtained by cardiac puncture. Blood samples collected in tubes containing heparin were then

centrifuged at $1,500 \mathrm{~g}$ for $10 \mathrm{~min}$ at $4^{\circ} \mathrm{C}$ to separate plasma. Plasma samples were collected and stored at $-80^{\circ} \mathrm{C}$ until assayed. Plasma calcium and phosphorus were determined by enzymatic reactions that produced a color changes using a vet 16 rotor Hemagen Analyst (Hemagen Diagnostics, Inc. Columbia, MD). The rotors were read using the Hemagen Analyst automated spectrophotometer (Hemagen Diagnostics, Inc. Columbia, MD).

\subsection{Oxidative Stress}

Oxidative stress was determined using a Thiobarbituric Acid Reactive Substances (TBARS) assay. TBARS were performed according to Cayman's TBARS Assay (Cayman Chemical, Ann Arbor, MI). Plasma samples were mixed with sodium dodecyl sulfate (SDS) solution and a color reagent containing TBA, 
acetic acid, and sodium hydroxide. Samples were incubated for 60 minutes in a $90^{\circ} \mathrm{C}$ water bath and then incubated in an ice bath for 10 minutes to stop the reaction. Following centrifugation for 10 minutes at $1,600 \mathrm{x} g$ at $4^{\circ} \mathrm{C}$, samples were measured. Absorbance was read at $540 \mathrm{~nm}$ using a Spectramax Plus microplate reader (Molecular Devices, $\mathrm{CA}$ ) with values expressed as $\mu \mathrm{M} / \mathrm{MDA}$ (malondialdehyde).

Plasma total antioxidant capacity was measured using Cayman's Antioxidant Assay (Cayman Chemical, Ann Arbor, MI). Plasma samples were diluted with $5 \mathrm{mM}$ potassium phosphate buffer, containing $0.9 \%$ sodium chloride and $0.1 \%$ glucose, at a $\mathrm{pH}$ of 7.4 (1:24 v/v). 6-Hydroxy-2,5,7,8tetramethylchroman-2-carboxylic acid (Trolox), was added to standard wells while diluted samples were added in duplicate to sample wells. Metmyoglobin and 2,2'-Azino-di-[3-ethylbenzthiazoline sulphonate] (ABTS) were added to all wells. Hydrogen pyroxide was then added to initiate the reaction. Samples were covered and incubated at room temperature on a shaker for 5 minutes. Absorbance was read at $750 \mathrm{~nm}$ using a Spectramax Plus microplate reader (Molecular Devices, CA). Antioxidant concentration was expressed as $\mathrm{mM} /$ Trolox.

\subsection{Plasma C-reactive Protein}

C-reactive protein (CRP) was measured to determine acute inflammation using a Helica ${ }^{\mathrm{TM}} \mathrm{C}$-reactive protein assay. Plasma samples were diluted to 1:4,000 and allowed to react with antibodies coated on specially treated 
microwells. After 30 minutes incubation, the wells were washed to remove unreacted serum proteins, and an enzyme-labeled rabbit anti-rat CRP (conjugate) was added to label the antigen-antibody complexes. Following another 30 minute incubation period, the wells were washed again to remove unreacted conjugate. A urea peroxide substrate with 3,3', 5,5'-tetramethylbenzidine (TMB) as chromogen was added to start color development. Stop solution was added after 5-10 minutes to interrupt the reaction. Absorbance was read at $450 \mathrm{~nm}$ using a Spectramax Plus microplate reader (Molecular Devices, CA) with values expressed as mg/ml.

\subsection{Statistical Analysis}

Data are expressed as mean \pm standard error of the mean (SEM). A twoway ANOVA was used to determine the effect of age, treatment, or age $\mathrm{x}$ treatment on measured bone variables. Fisher's t-tests (LSD) were used to evaluate differences among the means of the treatment groups. $P<0.05$ was considered significant. Statistical analyses were performed using SigmaStat 3.1 statistical software program (Systat Software Inc., San Jose, CA). Different letters a, b, c indicate significant differences at $P<0.05$ with aging. Different letters $\mathrm{w}, \mathrm{x}, \mathrm{y}, \mathrm{z}$ indicate significant differences at $P<0.05$ due to resveratrol supplementation. 


\subsection{RESULTS}

\subsection{Final Body Mass of $A M B$ male rats}

In study 1 , final body weight was higher $(P<0.001)$ in old compared to mature male rats. Resveratrol supplementation had no effect on the final body mass of old or mature male rats (Fig 5).

\subsection{Bone Morphometry in AMB male rats}

In study 1 , femur length $(P<0.001)$, width $(P<0.001)$, depth $(P<0.001)$, and wet weight $(P<0.001)$ were greater in old compared to mature male rats. Similarly, tibia length $(P<0.001)$, width $(P<0.001)$, depth $(P<0.001)$, and wet weight $(P<0.001)$ were greater in old compared to mature male rats (Table 1$)$. Resveratrol supplementation had no effect on bone morphometry, except mature male rats provided resveratrol had increased tibia length $(P=0.013)$ compared to mature rats provided no resveratrol. A two-way ANOVA indicated an age $\mathrm{x}$ resveratrol interaction on tibia length $(P=0.01)$ suggesting that resveratrol's effect was dependent upon age. Additionally, two-way ANOVA indicated an age x resveratrol interaction on tibia width $(P=0.012)$ signifying that resveratrol's effect was dependent upon age (Table 1).

\subsection{Bone Mineralization in $A M B$ male rats}

In study 1 , femur BMA $(P<0.001)$, BMC $(P=0.003)$, and ash weight $(P=0.027)$ were higher in old compared to mature male rats. Similarly, tibia BMA $(P<0.001)$, BMC $(P=0.004)$, and ash weight $(P=0.045)$ were higher in old 
compared to mature male rats. Femur calcium content was increased $(P=0.036)$ in old compared to mature rats provided resveratrol. There were no significant differences on femur or tibia BMD and phosphorus content (Table 2).

When femur BMA was corrected for length, no differences were observed: $\mathrm{MC}=0.53 \pm 0.06 \mathrm{~cm}^{2}, \mathrm{MR}=0.52 \pm 0.05 \mathrm{~cm}^{2}, \mathrm{OC}=0.53 \pm 0.01 \mathrm{~cm}^{2}$, $\mathrm{OR}=0.56 \pm 0.02 \mathrm{~cm}^{2}$. Similarly, no differences were observed when femur BMC was corrected for length: $\mathrm{MC}=0.15 \pm 0.02 \mathrm{~g}, \mathrm{MR}=0.15 \pm 0.02 \mathrm{~g}, \mathrm{OC}=0.15 \pm 0.01 \mathrm{~g}$, $\mathrm{OR}=0.16 \pm 0.01 \mathrm{~g}$. Femur ash weight corrected for length resulted in no differences: $\mathrm{MC}=0.14 \pm 0.01 \mathrm{~g}, \mathrm{MR}=0.14 \pm 0.01 \mathrm{~g}, \mathrm{OC}=0.14 \pm 0.01 \mathrm{~g}$, $\mathrm{OR}=0.15 \pm 0.01 \mathrm{~g}$.

When tibia BMA was corrected for length, no differences were observed: $\mathrm{MC}=0.45 \pm 0.06 \mathrm{~cm}^{2}, \mathrm{MR}=0.42 \pm 0.03 \mathrm{~cm}^{2}, \mathrm{OC}=0.50 \pm 0.03 \mathrm{~cm}^{2}, \mathrm{OR}=0.44 \pm 0.01$ $\mathrm{cm}^{2}$. Similarly, no differences were observed when tibia BMC was corrected for length: $\mathrm{MC}=0.11 \pm 0.01 \mathrm{~g}, \mathrm{MR}=0.10 \pm 0.01 \mathrm{~g}, \mathrm{OC}=0.12 \pm 0.01 \mathrm{~g}, \mathrm{OR}=0.11 \pm 0.01 \mathrm{~g}$. Tibia ash weight corrected for length was $0.09 \pm 0.01 \mathrm{~g}$ for all groups.

Tibia BMA $(P=0.031)$ and BMC $(P=0.034)$ were decreased in old male rats provided resveratrol compared to no resveratrol. A two-way ANOVA indicated an age $\mathrm{x}$ resveratrol interaction on tibia $\mathrm{BMC}(P=0.026)$. However, resveratrol had no effects when BMA and BMC were corrected for length. Resveratrol supplementation had no effect on femur or tibia BMD, ash, and phosphorus content in mature or old male rats (Table 2). 


\subsection{Bone Architecture in AMB male rats}

In study 1 , femur BV/TV $(P<0.001)$, TbN $(P<0.001)$, and CONN $(P<0.001)$ were decreased and TbSp $(P<0.001)$ and SMI $(P=0.003)$ were increased in old compared to mature male. No differences were observed in femur TbTH. Tibia BV/TV $(P<0.001)$, TbN $(P<0.001)$, and CONN $(P<0.001)$ were decreased and TbTH $(P<0.001)$, TbSp $(P<0.001)$ and SMI $(P<0.001)$ were increased in old compared to mature male rats (Table 3).

Resveratrol supplementation increased tibia TbTH $(P=0.018)$ in old male rats. Additionally, two-way ANOVA indicated an age x resveratrol interaction on tibia TbTH $(P=0.037)$ signifying that resveratrol's effect was dependent upon age There were no other significant effects of resveratrol supplementation on femur and tibia bone architecture measurements in mature or old male rats (Table 3).

\subsection{Bone Biomechanics in AMB male rats}

In study 1 , femur peak force $(P<0.001)$ and ultimate stiffness $(P=0.034)$ and tibia peak force $(P=0.005)$ and ultimate stiffness $(P=0.047)$ were greater in old compared to mature male rats. No significant differences were observed in femur or tibia bending failure energy and UBS. Femur $(P=0.002)$ and tibia Young's modulus $(P=0.034)$ were decreased in old compared to mature male rats (Table 4). Resveratrol supplementation had no effect on bone strength measurements in mature or old male rats (Table 4). 


\subsection{Plasma Clinical Markers in AMB male rats}

In study 1 , plasma phosphorus $(P<0.001)$ and ALP $(P<0.001)$ were decreased in old compared to mature male rats. There was no effect on total antioxidant capacity; however, plasma TBARS was decreased $(P<0.001)$ in old compared to mature male rats. Plasma CRP were increased $(P<0.001)$ in old compared to mature male rats (Table 5). Providing resveratrol to either mature or old male rats had no significant effects on plasma CRP, total antioxidant capacity, TBARS, calcium, phosphorus, or ALP (Table 5).

Study 1 (AMB)

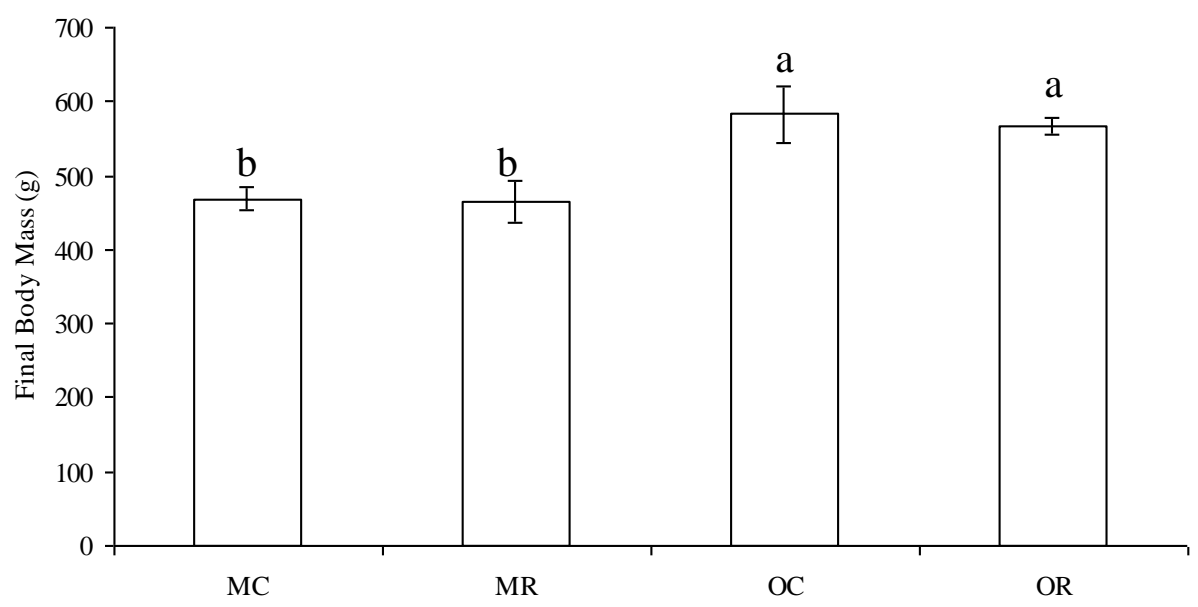

Figure 6. Final Body Mass of mature and old ambulatory male rats provided resveratrol or no resveratrol. Values are expressed as the mean \pm SEM of $n=6$ 7. Different letters a, b, within the same column indicate significant differences at $P<0.05$ due to aging by two-way ANOVA followed by Tukey's test. 
Table 1. Bone morphometry of old and mature ambulatory male rats provided resveratrol or no resveratrol ${ }^{\S}$

\begin{tabular}{|c|c|c|c|c|}
\hline Treatment & Length $(\mathrm{cm})$ & Width (mm) & Depth (mm) & Wet Weight (g) \\
\hline \multicolumn{5}{|l|}{ Femur } \\
\hline $\mathrm{MC}$ & $3.67 \pm 0.03^{b}$ & $5.54 \pm 0.07^{b}$ & $3.62 \pm 0.05^{b}$ & $0.97 \pm 0.02^{b}$ \\
\hline MR & $3.69 \pm 0.03^{b}$ & $5.64 \pm 0.08^{b}$ & $3.65 \pm 0.07^{\mathrm{b}}$ & $1.04 \pm 0.03^{b}$ \\
\hline $\mathrm{OC}$ & $3.98 \pm 0.08^{\mathrm{a}}$ & $6.21 \pm 0.07^{\mathrm{a}}$ & $4.19 \pm 0.04^{\mathrm{a}}$ & $1.23 \pm 0.03^{\mathrm{a}}$ \\
\hline OR & $3.83 \pm 0.02^{a b}$ & $6.30 \pm 0.06^{\mathrm{a}}$ & $4.21 \pm 0.04^{\mathrm{a}}$ & $1.19 \pm 0.02^{\mathrm{a}}$ \\
\hline \multicolumn{5}{|l|}{$\underline{\text { Tibia }}$} \\
\hline $\mathrm{MC}$ & $4.09 \pm 0.09^{\mathrm{b}, \mathrm{z}}$ & $4.35 \pm 0.03^{b, y}$ & $2.99 \pm 0.06^{b}$ & $0.74 \pm 0.02^{b}$ \\
\hline MR & $4.25 \pm 0.03^{a b, y}$ & $4.50 \pm 0.06^{\mathrm{b}, \mathrm{y}}$ & $3.06 \pm 0.07^{b}$ & $0.75 \pm 0.02^{b}$ \\
\hline $\mathrm{OC}$ & $4.40 \pm 0.02^{\mathrm{a}, \mathrm{x}}$ & $4.98 \pm 0.05^{\mathrm{a}, \mathrm{x}}$ & $3.37 \pm 0.05^{\mathrm{a}}$ & $0.85 \pm 0.03^{\mathrm{a}}$ \\
\hline OR & $4.32 \pm 0.02^{\mathrm{a}, \mathrm{x}}$ & $4.83 \pm 0.07^{\mathrm{a}, \mathrm{x}}$ & $3.31 \pm 0.06^{\mathrm{a}}$ & $0.79 \pm 0.02^{\mathrm{ab}}$ \\
\hline
\end{tabular}

${ }^{\S}$ Values are expressed as the mean \pm SEM of $n=12-14$ bones/group. Different letters $a$, $b$, within the same column indicate significant differences at $P<0.05$ due to aging by two-way ANOVA followed by Tukey's test. Different letters x, y, within the same column indicate significant differences at $P<0.05$ due to resveratrol supplementation by two-way ANOVA followed by Tukey's test. 
Table 2. Femur and tibia bone mineral area, density, and content in mature and old ambulatory male rats provided resveratrol or no resveratrol ${ }^{\S}$

\begin{tabular}{lllllll}
\hline Treatment & BMA $\left(\mathrm{cm}^{2}\right)$ & BMD $\left(\mathrm{mg} / \mathrm{cm}^{2}\right)$ & BMC $(\mathrm{g})$ & Ash Weight $(\mathrm{g})$ & $\mathrm{Ca}(\mathrm{mg} / \mathrm{g}$ bone $)$ & $\mathrm{P}(\mathrm{mg} / \mathrm{g} \mathrm{bone})$ \\
\hline$\underline{\text { Femur }}$ & & & & & & \\
MC & $2.11 \pm 0.04^{\mathrm{b}}$ & $0.28 \pm 0.004$ & $0.60 \pm 0.01^{\mathrm{b}}$ & $0.50 \pm 0.01^{\mathrm{b}}$ & $193.88 \pm 10.15^{\mathrm{ab}}$ & $90.98 \pm 3.74$ \\
MR & $2.19 \pm 0.06^{\mathrm{b}}$ & $0.29 \pm 0.005$ & $0.63 \pm 0.03^{\mathrm{ab}}$ & $0.53 \pm 0.01^{\mathrm{b}}$ & $173.66 \pm 16.24^{\mathrm{b}}$ & $88.39 \pm 3.84$ \\
OC & $2.44 \pm 0.05^{\mathrm{a}}$ & $0.28 \pm 0.004$ & $0.68 \pm 0.02^{\mathrm{a}}$ & $0.68 \pm 0.11^{\mathrm{a}}$ & $176.30 \pm 7.23^{\mathrm{ab}}$ & $83.20 \pm 2.63$ \\
OR & $2.39 \pm 0.03^{\mathrm{a}}$ & $0.28 \pm 0.003$ & $0.67 \pm 0.01^{\mathrm{a}}$ & $0.57 \pm 0.01^{\mathrm{a}}$ & $212.84 \pm 14.70^{\mathrm{a}}$ & $94.63 \pm 5.35$ \\
& & & & & & \\
Tibia & & & & & & \\
MC & $1.81 \pm 0.03^{\mathrm{b}, \mathrm{y}}$ & $0.23 \pm 0.002$ & $0.42 \pm 0.01^{\mathrm{b}, \mathrm{z}}$ & $0.37 \pm 0.01^{\mathrm{b}}$ & $166.31 \pm 24.06$ & $80.74 \pm 9.65$ \\
MR & $1.80 \pm 0.05^{\mathrm{b}, \mathrm{xy}}$ & $0.24 \pm 0.004$ & $0.44 \pm 0.02^{\mathrm{b}, \mathrm{z}}$ & $0.38 \pm 0.01^{\mathrm{b}}$ & $217.28 \pm 5.92$ & $91.21 \pm 10.07$ \\
OC & $2.07 \pm 0.06^{\mathrm{a}, \mathrm{w}}$ & $0.24 \pm 0.003$ & $0.49 \pm 0.01^{\mathrm{a}, \mathrm{x}}$ & $0.50 \pm 0.08^{\mathrm{a}}$ & $167.95 \pm 24.61$ & $85.38 \pm 17.11$ \\
OR & $1.90 \pm 0.02^{\mathrm{b}, \mathrm{x}}$ & $0.24 \pm 0.002$ & $0.45 \pm 0.01^{\mathrm{a}, \mathrm{y}}$ & $0.41 \pm 0.01^{\mathrm{a}}$ & $202.45 \pm 11.61$ & $86.44 \pm 10.63$ \\
\hline
\end{tabular}

${ }^{\S}$ Values are expressed as the mean \pm SEM of $n=6-7$ bones/group. Different letters $a, b$, within the same column indicate significant differences at $P<0.05$ with aging by two-way ANOVA followed by Tukey's test. Different letters $\mathrm{x}, \mathrm{y}$, within the same column indicate significant differences at $P<0.05$ with resveratrol supplementation by two-way ANOVA followed by Tukey's test.

$\mathrm{BMA}=$ Bone mineral area, $\mathrm{BMC}=\mathrm{Bone}$ mineral content, $\mathrm{BMD}=$ Bone mineral density, $\mathrm{Ca}=$ calcium,$P=$ phosphorus. 
Table 3. Femur and tibia trabecular bone architecture in mature and old ambulatory male rats provided resveratrol or no resveratrol $^{\S}$

\begin{tabular}{|c|c|c|c|c|c|c|}
\hline Treatment & $\mathrm{BV} / \mathrm{TV}$ & $\mathrm{TbN}($ per mm) & $\mathrm{TbTH}(\mu \mathrm{m})$ & CONN & $\mathrm{TbSp}($ per $\mu \mathrm{m})$ & SMI \\
\hline \multicolumn{7}{|l|}{$\underline{\text { Femur }}$} \\
\hline $\mathrm{MC}$ & $0.26 \pm 0.02^{\mathrm{a}}$ & $4.25 \pm 0.37^{\mathrm{a}}$ & $0.08 \pm 0.002$ & $91.89 \pm 13.83^{a}$ & $0.24 \pm 0.02^{b}$ & $1.13 \pm 0.10^{b}$ \\
\hline MR & $0.26 \pm 0.01^{\mathrm{a}}$ & $4.32 \pm 0.09^{\mathrm{a}}$ & $0.08 \pm 0.002$ & $82.51 \pm 8.74^{\mathrm{a}}$ & $0.25 \pm 0.02^{b}$ & $1.31 \pm 0.08^{b}$ \\
\hline $\mathrm{OC}$ & $0.09 \pm 0.01^{\mathrm{b}}$ & $1.94 \pm 0.05^{b}$ & $0.08 \pm 0.003$ & $13.63 \pm 0.85^{b}$ & $0.52 \pm 0.01^{\mathrm{a}}$ & $1.85 \pm 0.06^{\mathrm{a}}$ \\
\hline OR & $0.10 \pm 0.01^{b}$ & $1.97 \pm 0.06^{\mathrm{b}}$ & $0.08 \pm 0.002$ & $14.08 \pm 1.13^{b}$ & $0.51 \pm 0.02^{\mathrm{a}}$ & $1.76 \pm 0.07^{\mathrm{a}}$ \\
\hline \multicolumn{7}{|l|}{$\underline{\text { Tibia }}$} \\
\hline $\mathrm{MC}$ & $0.32 \pm 0.03^{\mathrm{a}}$ & $4.43 \pm 0.38^{a}$ & $0.09 \pm 0.003^{\mathrm{b}, \mathrm{z}}$ & $90.88 \pm 16.76^{\mathrm{a}}$ & $0.21 \pm 0.02^{b}$ & $0.88 \pm 0.19^{b}$ \\
\hline MR & $0.30 \pm 0.01^{\mathrm{a}}$ & $4.17 \pm 0.19^{\mathrm{a}}$ & $0.09 \pm 0.006^{\mathrm{b}, \mathrm{z}}$ & $79.00 \pm 8.94^{\mathrm{a}}$ & $0.22 \pm 0.01^{b}$ & $1.05 \pm 0.04^{\mathrm{b}}$ \\
\hline $\mathrm{OC}$ & $0.12 \pm 0.01^{b}$ & $2.01 \pm 0.06^{\mathrm{b}}$ & $0.10 \pm 0.004^{\mathrm{a}, \mathrm{y}}$ & $6.89 \pm 0.79^{b}$ & $0.48 \pm 0.02^{\mathrm{a}}$ & $1.97 \pm 0.09^{\mathrm{a}}$ \\
\hline OR & $0.13 \pm 0.01^{b}$ & $1.95 \pm 0.05^{\mathrm{b}}$ & $0.11 \pm 0.010^{\mathrm{a}, \mathrm{x}}$ & $10.05 \pm 0.87^{b}$ & $0.49 \pm 0.01^{\mathrm{a}}$ & $2.09 \pm 0.10^{\mathrm{a}}$ \\
\hline
\end{tabular}

${ }^{\S}$ Values are expressed as the mean \pm SEM of $n=6-7$ bones/group. Different letters $a, b$, within the same column indicate significant differences at $P<0.05$ with aging by two-way ANOVA followed by Tukey's test. Different letters $\mathrm{x}, \mathrm{y}$, within the same column indicate significant differences at $P<0.05$ with resveratrol supplementation by two-way ANOVA followed by Tukey's test.

$\mathrm{BV} / \mathrm{TV}=$ Trabecular bone volume per unit of total volume, $\mathrm{TbN}=$ Trabecular number, $\mathrm{TbTh}=\mathrm{Trabecular}$ thickness, $\mathrm{CONN}=$ Connectivity, $\mathrm{TbS} P=$ Trabecular separation, $\mathrm{SMI}=$ Structure model index, 
Table 4. Biomechanical measurements of bone strength in mature and old ambulatory male rats provided resveratrol or no resveratrol $^{\S}$

\begin{tabular}{llllll}
\hline Treatment & $\begin{array}{l}\text { Peak Force } \\
(\mathrm{N})\end{array}$ & $\begin{array}{l}\text { Ultimate Stiffness } \\
(\mathrm{N} / \mathrm{s})\end{array}$ & $\begin{array}{l}\text { Bending Failure } \\
\text { Energy (N.s) }\end{array}$ & $\begin{array}{l}\text { Ultimate Bending } \\
\left.\text { Stress (N/mm }{ }^{2}\right)\end{array}$ & $\begin{array}{l}\text { Young's Modulus } \\
\left(\mathrm{N} / \mathrm{mm}^{2}\right)\end{array}$ \\
\hline$\underline{\text { Femur }}$ & & & & \\
MC & $194.15 \pm 7.27^{\mathrm{b}}$ & $488.99 \pm 36.02^{\mathrm{b}}$ & $5.52 \pm 0.68$ & $66.00 \pm 7.58$ & $574.90 \pm 46.56^{\mathrm{a}}$ \\
MR & $194.57 \pm 6.28^{\mathrm{b}}$ & $473.33 \pm 32.40^{\mathrm{b}}$ & $5.82 \pm 0.71$ & $72.09 \pm 2.50$ & $528.75 \pm 47.27^{\mathrm{a}}$ \\
OC & $244.68 \pm 13.62^{\mathrm{a}}$ & $539.07 \pm 30.55^{\mathrm{a}}$ & $5.57 \pm 0.43$ & $70.26 \pm 4.30$ & $415.53 \pm 26.22^{\mathrm{b}}$ \\
OR & $228.26 \pm 5.36^{\mathrm{a}}$ & $571.31 \pm 34.84^{\mathrm{a}}$ & $5.06 \pm 0.30$ & $64.04 \pm 2.96$ & $424.34 \pm 29.40^{\mathrm{b}}$ \\
& & & & & \\
Tibia & & & & $115.15 \pm 15.96$ & $822.98 \pm 55.30^{\mathrm{a}}$ \\
MC & $137.53 \pm 6.10^{\mathrm{b}}$ & $331.11 \pm 21.72^{\mathrm{b}}$ & $4.06 \pm 0.48$ & $127.69 \pm 14.31$ & $762.38 \pm 63.96^{\mathrm{a}}$ \\
MR & $135.53 \pm 5.34^{\mathrm{b}}$ & $312.66 \pm 32.08^{\mathrm{b}}$ & $3.74 \pm 0.47$ & $112.38 \pm 14.64$ & $541.93 \pm 132.78^{\mathrm{b}}$ \\
OC & $170.52 \pm 13.41^{\mathrm{a}}$ & $439.39 \pm 55.00^{\mathrm{a}}$ & $3.64 \pm 0.46$ & $119.80 \pm 19.20$ & $656.22 \pm 91.84^{\mathrm{b}}$ \\
OR & $165.50 \pm 14.78^{\mathrm{a}}$ & $376.31 \pm 51.78^{\mathrm{a}}$ & $4.75 \pm 1.16$ & & \\
\hline
\end{tabular}

${ }^{\S}$ Values are expressed as the mean \pm SEM of $n=12-14$ bones/group. Different letters $a$, $b$, within the same column indicate significant differences at $P<0.05$ with aging by two-way ANOVA followed by Tukey's test. 
Table 5. Plasma measurements of bone formation, inflammation, and oxidative stress in mature and old ambulatory male rats provided resveratrol or no resveratrol ${ }^{\S}$

\begin{tabular}{lllllll}
\hline Treatment & $\begin{array}{l}\mathrm{Ca} \\
(\mathrm{mg} / \mathrm{dL})\end{array}$ & $\begin{array}{l}\mathrm{P} \\
(\mathrm{mg} / \mathrm{dL})\end{array}$ & $\begin{array}{l}\text { ALP } \\
(\mathrm{U} / \mathrm{L})\end{array}$ & $\begin{array}{l}\text { Total Antioxidants } \\
(\mathrm{mM} / \text { Trolox })\end{array}$ & $\begin{array}{l}\text { TBARS } \\
(\mu \mathrm{M} \text { MDA })\end{array}$ & $\begin{array}{l}\text { CRP } \\
(\mathrm{mg} / \mathrm{mL})\end{array}$ \\
\hline MC & $12.86 \pm 0.50$ & $11.66 \pm 1.00^{\mathrm{a}}$ & $261.86 \pm 22.12^{\mathrm{a}}$ & $2.44 \pm 0.43$ & $5.63 \pm 0.21^{\mathrm{a}}$ & $0.45 \pm 0.18^{\mathrm{b}}$ \\
MR & $12.06 \pm 0.54$ & $10.31 \pm 0.51^{\mathrm{a}}$ & $264.86 \pm 11.17^{\mathrm{a}}$ & $2.97 \pm 0.79$ & $6.12 \pm 0.19^{\mathrm{a}}$ & $0.41 \pm 0.06^{\mathrm{b}}$ \\
OC & $11.23 \pm 1.03$ & $6.86 \pm 0.58^{\mathrm{b}}$ & $185.57 \pm 11.30^{\mathrm{b}}$ & $2.55 \pm 0.42$ & $4.43 \pm 0.55^{\mathrm{b}}$ & $3.47 \pm 0.72^{\mathrm{a}}$ \\
OR & $11.07 \pm 0.50$ & $7.27 \pm 0.19^{\mathrm{b}}$ & $174.86 \pm 15.09^{\mathrm{b}}$ & $2.61 \pm 0.67$ & $4.29 \pm 0.48^{\mathrm{b}}$ & $2.33 \pm 0.41^{\mathrm{a}}$ \\
\hline
\end{tabular}

${ }^{\S}$ Values are expressed as the mean \pm SE of $n=6$-7/group. Different letters $a, b$, within the same column indicate significant differences at $P<0.05$ with aging by two-way ANOVA followed by Tukey's test. Different letters $\mathrm{x}, \mathrm{y}$, within the same column indicate significant differences at $P<0.05$ with resveratrol supplementation by two-way ANOVA followed by Tukey's test.

$\mathrm{Ca}=$ calcium, $P=$ Phosphorus, $\mathrm{AL} P=$ Alkaline phosphatase, TBARS $=$ Thiobarbituric acid reactive substances, $\mathrm{CR} P=\mathrm{C}$-reactive protein 


\subsection{Final Body Mass of HLS male rats}

In study 2 , final body weight $(P<0.001)$ was higher in old compared to mature HLS male rats. Resveratrol supplementation had no effect on final body mass in old or mature HLS male rats (Fig 7).

\subsection{Bone Morphometry in HLS male rats}

In study 2 , femur length $(P=0.033)$, width $(P<0.001)$, depth $(P<0.001)$, and wet weight $(P<0.001)$ were higher in old compared to mature male rats. Similarly, tibia length $(P<0.001)$, width $(P<0.001)$, depth $(P=0.025)$, and wet weight $(P=0.004)$ were higher in old compared to mature HLS male rats. Providing resveratrol had no significant effects on femur or tibia morphometry (Table 6).

\subsection{Bone Mineralization in HLS male rats}

In Study 2, femur BMD $(P=0.033)$ decreased in old compared to mature male rats. Tibia BMA $(P=0.004)$ increased in old compared to mature male rats. Tibia BMD decreased $(P=0.036)$ in old compared to mature male rats. No differences were observed when tibia BMA was corrected for length, $\mathrm{MHC}=0.44 \pm 0.01, \mathrm{MHR}=0.42 \pm 0.03, \mathrm{OHC}=0.42 \pm 0.04, \mathrm{OHR}=0.44 \pm 0.03$. No aging effects were observed in other bone mineralization measurements in HLS male rats.

Femur BMA was increased $(P=0.031)$ in old rats provided resveratrol compared to old rats provided no resveratrol. However, when BMA was 
corrected for length, no effect of resveratrol supplementation was observed. In mature rats, resveratrol supplementation decreased tibia calcium $(P=0.018)$ and phosphorus $(P=0.024)$ content compared to male rats provided no resveratrol (Table 7). Resveratrol supplementation had no significant effect on other measurements of bone mineralization in mature or old HLS male rats.

\subsection{Bone Architecture in HLS male rats}

In study 2 , femur and tibia BV/TV $(P<0.001), \operatorname{TbN}(P<0.001)$, and CONN $(P<0.001)$ decreased and TbSp $(P<0.001)$ and SMI $(P<0.001)$ increased in old compared to mature male rats. No differences were seen in femur TbTH between mature and old male rats. Tibia TbTH was increased $(P=0.003)$ in old compared to mature rats provided resveratrol (Table 8). Resveratrol supplementation had no significant effect on other femur and tibia bone architecture measurements in mature or old HLS male rats.

\subsection{Bone Biomechanics in HLS male rats}

In study 2 , femur UBS $(P<0.001)$ and Young's modulus $(P=0.032)$ were decreased in old compared to mature HLS male rats. Tibia peak force $(P=0.049)$ and femur ultimate stiffness $(P<0.001)$ were increased in old compared to mature rats. There were no significant effects of aging on bending failure energy.

Resveratrol supplementation had no significant effect on femur and tibia strength measurements in HLS mature or old rats (Table 9). 


\subsection{Plasma Clinical Markers in HLS male rats}

In study 2 , plasma calcium $(P=0.033)$, phosphorus $(P<0.001)$, and ALP $(P=0.009)$ were decreased in old compared to mature male rats. There was no effect on total antioxidant capacity; however, plasma TBARS $(P=0.036)$ were decreased in old compared to mature male rats. Plasma CRP was increased $(P=0.015)$ in old male rats compared to mature male rats

Resveratrol supplementation had no effect on plasma calcium, phosphorus, or ALP. Resveratrol had no effect on plasma total antioxidant capacity. However, plasma TBARS increased $(P=0.036)$ in mature male rats provided resveratrol compared to no resveratrol. In old male rats, resveratrol supplementation decreased $(P=0.042)$ plasma TBARS compared to rats provided no resveratrol (Table 10). A two-way ANOVA indicated an age x resveratrol interaction $(P=0.005)$ on plasma TBARS. (Table 10$)$.

Study 2 (HLS)

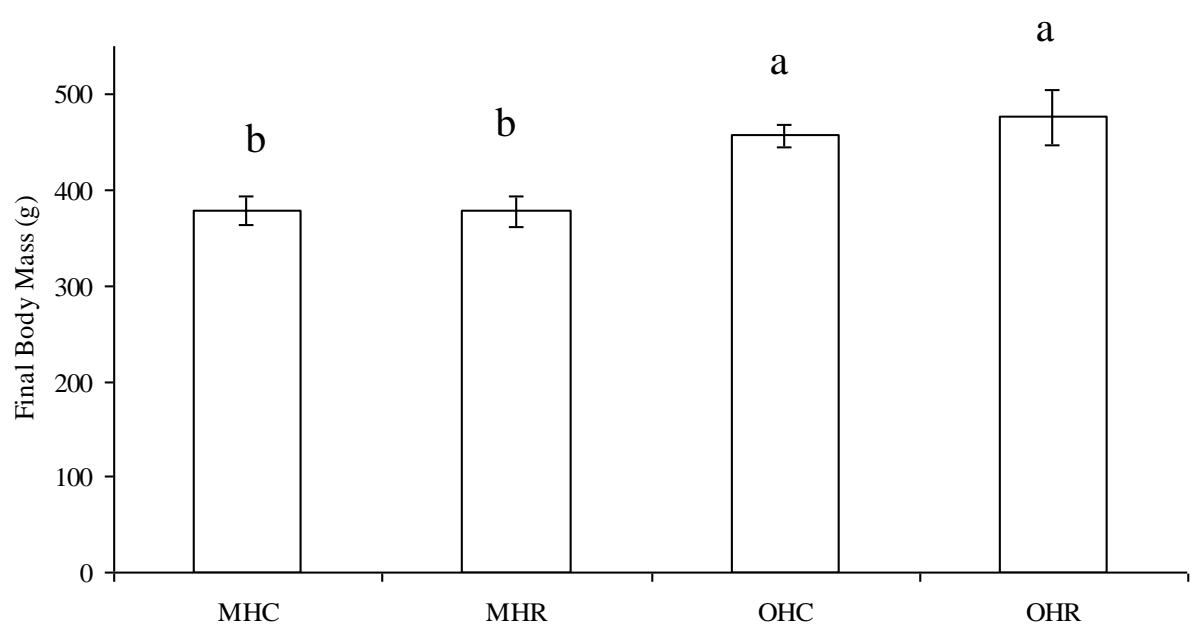

Figure 7. Final Body Mass of mature and old hindlimb suspended rats provided resveratrol or no resveratrol. Values are expressed as the mean \pm SEM of $n=6-7$. Different letters a, b, within the same column indicate significant differences at $P<0.05$ due to aging by two-way ANOVA followed by Tukey's test. 
Table 6. Bone morphometry in old and mature hindlimb suspended male rats provided resveratrol or no resveratrol ${ }^{\S}$

\begin{tabular}{|c|c|c|c|c|}
\hline Treatment & Length $(\mathrm{cm})$ & Width (mm) & Depth $(\mathrm{mm})$ & Wet Weight (g) \\
\hline \multicolumn{5}{|l|}{ Femur } \\
\hline $\mathrm{MHC}$ & $3.72 \pm 0.03^{b}$ & $5.49 \pm 0.08^{b}$ & $3.61 \pm 0.06^{b}$ & $1.12 \pm 0.07^{b}$ \\
\hline MHR & $3.68 \pm 0.03^{b}$ & $5.56 \pm 0.08^{b}$ & $3.59 \pm 0.07^{\mathrm{b}}$ & $1.02 \pm 0.03^{b}$ \\
\hline $\mathrm{OHC}$ & $3.84 \pm 0.07^{\mathrm{a}}$ & $6.20 \pm 0.05^{\mathrm{a}}$ & $4.25 \pm 0.07^{\mathrm{a}}$ & $1.10 \pm 0.03^{\mathrm{a}}$ \\
\hline OHR & $3.84 \pm 0.02^{\mathrm{a}}$ & $6.24 \pm 0.06^{\mathrm{a}}$ & $4.15 \pm 0.06^{\mathrm{a}}$ & $1.17 \pm 0.02^{\mathrm{a}}$ \\
\hline \multicolumn{5}{|l|}{ Tibia } \\
\hline MHC & $4.23 \pm 0.02^{b}$ & $4.48 \pm 0.06^{b}$ & $3.09 \pm 0.07^{b}$ & $0.75 \pm 0.02^{b}$ \\
\hline MHR & $4.19 \pm 0.03^{b}$ & $4.36 \pm 0.06^{b}$ & $3.13 \pm 0.07^{b}$ & $0.73 \pm 0.02^{b}$ \\
\hline $\mathrm{OHC}$ & $4.32 \pm 0.03^{\mathrm{a}}$ & $4.79 \pm 0.05^{\mathrm{a}}$ & $3.29 \pm 0.07^{\mathrm{a}}$ & $0.79 \pm 0.02^{\mathrm{a}}$ \\
\hline OHR & $4.28 \pm 0.07^{\mathrm{a}}$ & $4.84 \pm 0.04^{\mathrm{a}}$ & $3.23 \pm 0.04^{\mathrm{a}}$ & $0.81 \pm 0.02^{\mathrm{a}}$ \\
\hline
\end{tabular}

${ }^{\S}$ Values are expressed as the mean \pm SEM of $n=12-14$ bones/group. Different letters $a$, $b$, within the same column indicate significant differences at $P<0.05$ with aging by two-way ANOVA followed by Tukey's test. Different letters $\mathrm{x}, \mathrm{y}$, within the same column indicate significant differences at $P<0.05$ with resveratrol supplementation by two-way ANOVA followed by Tukey's test. 
Table 7. Femur and tibia bone mineral area, density, and content in old and mature hindlimb suspended male rats provided resveratrol or no resveratrol $^{\S}$

\begin{tabular}{lllllll}
\hline Treatment & BMA $\left(\mathrm{cm}^{2}\right)$ & BMD $\left(\mathrm{mg} / \mathrm{cm}^{2}\right)$ & BMC $(\mathrm{g})$ & Ash Weight $(\mathrm{g})$ & $\mathrm{Ca}(\mathrm{mg} / \mathrm{g}$ bone $)$ & $\mathrm{P}(\mathrm{mg} / \mathrm{g} \mathrm{bone})$ \\
\hline$\underline{\text { Femur }}$ & & & & & \\
MHC & $2.18 \pm 0.05^{\mathrm{b}}$ & $0.29 \pm 0.008^{\mathrm{a}}$ & $0.62 \pm 0.03$ & $0.52 \pm 0.02$ & $186.62 \pm 4.81$ & $89.65 \pm 1.82$ \\
MHR & $2.16 \pm 0.07^{\mathrm{b}}$ & $0.28 \pm 0.007^{\mathrm{a}}$ & $0.60 \pm 0.03$ & $0.51 \pm 0.02$ & $182.16 \pm 16.50$ & $85.49 \pm 7.56$ \\
OHC & $2.29 \pm 0.06^{\mathrm{ab}}$ & $0.26 \pm 0.007^{\mathrm{b}}$ & $0.60 \pm 0.03$ & $0.51 \pm 0.01$ & $181.54 \pm 3.16$ & $80.33 \pm 1.66$ \\
OHR & $2.40 \pm 0.03^{\mathrm{a}}$ & $0.27 \pm 0.003^{\mathrm{b}}$ & $0.65 \pm 0.01$ & $0.53 \pm 0.01$ & $192.49 \pm 7.39$ & $86.84 \pm 2.69$ \\
& & & & & \\
Tibia & $1.78 \pm 0.03^{\mathrm{b}, \mathrm{z}}$ & $0.25 \pm 0.005^{\mathrm{a}}$ & $0.44 \pm 0.02$ & $0.39 \pm 0.01$ & $211.91 \pm 4.78^{\mathrm{x}}$ & $89.34 \pm 9.64^{\mathrm{x}}$ \\
MHC & $1.77 \pm 0.05^{\mathrm{b}, \mathrm{z}}$ & $0.24 \pm 0.005^{\mathrm{ab}}$ & $0.42 \pm 0.02$ & $0.38 \pm 0.01$ & $185.84 \pm 10.53^{\mathrm{y}}$ & $79.20 \pm 9.47^{\mathrm{y}}$ \\
MHR & $1.88 \pm 0.05^{\mathrm{a}, \mathrm{y}}$ & $0.23 \pm 0.004^{\mathrm{b}}$ & $0.43 \pm 0.02$ & $0.39 \pm 0.01$ & $194.86 \pm 3.35^{\mathrm{z}}$ & $80.08 \pm 8.28^{\mathrm{z}}$ \\
OHC & $1.94 \pm 0.03^{\mathrm{a}, \mathrm{x}}$ & $0.24 \pm 0.004^{\mathrm{b}}$ & $0.46 \pm 0.01$ & $0.41 \pm 0.01$ & $205.83 \pm 3.52^{\mathrm{z}}$ & $84.80 \pm 9.19^{\mathrm{z}}$ \\
OHR & & & & & & \\
\hline
\end{tabular}

${ }^{\S}$ Values are expressed as the mean \pm SEM of $n=6-7$ bones/group. Different letters $a, b$, within the same column indicate significant differences at $P<0.05$ with aging by two-way ANOVA followed by Tukey's test. Different letters $\mathrm{x}, \mathrm{y}$, within the same column indicate significant differences at $P<0.05$ with resveratrol supplementation by two-way ANOVA followed by Tukey's test.

$\mathrm{Ca}=$ calcium, $P=$ phosphorus, $\mathrm{BMA}=$ Bone mineral area, $\mathrm{BMC}=$ Bone mineral content, $\mathrm{BMD}=\mathrm{Bone}$ mineral density 
Table 8. Femur and tibia trabecular bone architecture in old and mature hindlimb suspended male rats provided resveratrol or no resveratrol $^{\S}$

\begin{tabular}{|c|c|c|c|c|c|c|}
\hline Treatment & $\mathrm{BV} / \mathrm{TV}$ & $\mathrm{TbN}($ per $\mathrm{mm})$ & $\mathrm{TbTH}(\mu \mathrm{m})$ & CONN & TbSp (per $\mu \mathrm{m})$ & SMI \\
\hline \multicolumn{7}{|l|}{$\underline{\text { Femur }}$} \\
\hline MHC & $0.22 \pm 0.02^{\mathrm{a}}$ & $4.01 \pm 0.29^{\mathrm{a}}$ & $0.079 \pm 0.004$ & $77.88 \pm 9.11^{\mathrm{a}}$ & $0.25 \pm 0.02^{b}$ & $1.49 \pm 0.19^{b}$ \\
\hline MHR & $0.20 \pm 0.01^{\mathrm{a}}$ & $3.91 \pm 0.23^{\mathrm{a}}$ & $0.074 \pm 0.004$ & $76.86 \pm 8.89^{\mathrm{a}}$ & $0.26 \pm 0.02^{b}$ & $1.63 \pm 0.13^{\mathrm{ab}}$ \\
\hline $\mathrm{OHC}$ & $0.06 \pm 0.01^{b}$ & $1.73 \pm 0.09^{b}$ & $0.069 \pm 0.002$ & $10.05 \pm 1.60^{b}$ & $0.59 \pm 0.03^{\mathrm{a}}$ & $2.13 \pm 0.13^{\mathrm{a}}$ \\
\hline OHR & $0.08 \pm 0.01^{b}$ & $1.90 \pm 0.05^{b}$ & $0.074 \pm 0.003$ & $12.48 \pm 1.16^{b}$ & $0.53 \pm 0.01^{\mathrm{a}}$ & $1.86 \pm 0.11^{\mathrm{ab}}$ \\
\hline \multicolumn{7}{|l|}{$\underline{\text { Tibia }}$} \\
\hline MHC & $0.29 \pm 0.01^{\mathrm{a}}$ & $4.26 \pm 0.29^{a}$ & $0.090 \pm 0.004^{\mathrm{ab}}$ & $81.59 \pm 13.69^{a}$ & $0.21 \pm 0.01^{b}$ & $1.18 \pm 0.13^{b}$ \\
\hline MHR & $0.28 \pm 0.02^{\mathrm{a}}$ & $4.32 \pm 0.22^{\mathrm{a}}$ & $0.085 \pm 0.003^{b}$ & $84.40 \pm 9.39^{\mathrm{a}}$ & $0.21 \pm 0.01^{\mathrm{b}}$ & $1.26 \pm 0.10^{b}$ \\
\hline $\mathrm{OHC}$ & $0.09 \pm 0.01^{b}$ & $1.81 \pm 0.05^{b}$ & $0.095 \pm 0.003^{\mathrm{ab}}$ & $6.89 \pm 0.79^{b}$ & $0.55 \pm 0.02^{\mathrm{a}}$ & $2.29 \pm 0.18^{\mathrm{a}}$ \\
\hline OHR & $0.12 \pm 0.01^{b}$ & $1.96 \pm 0.06^{b}$ & $0.101 \pm 0.002^{\mathrm{a}}$ & $9.33 \pm 0.73^{b}$ & $0.49 \pm 0.02^{\mathrm{a}}$ & $2.18 \pm 0.07^{\mathrm{a}}$ \\
\hline
\end{tabular}

${ }^{\S}$ Values are expressed as the mean \pm SEM of $n=6-7$ bones/group. Different letters $a, b$, within the same column indicate significant differences at $P<0.05$ with aging by two-way ANOVA followed by Tukey's test. Different letters $\mathrm{x}, \mathrm{y}$, within the same column indicate significant differences at $P<0.05$ with resveratrol supplementation by two-way ANOVA followed by Tukey's test.

$\mathrm{BV} / \mathrm{TV}=$ Trabecular bone volume per unit of total volume, $\mathrm{TbN}=$ Trabecular number, $\mathrm{TbTh}=\mathrm{Trabecular}$ thickness, $\mathrm{CONN}=$ Connectivity, $\mathrm{TbS} P=$ Trabecular separation, $\mathrm{SMI}=$ Structure model index, 
Table 9. Biomechanical measurements of bone strength in old and mature hindlimb suspended male rats provided resveratrol or no resveratrol supplementation. ${ }^{\S}$

\begin{tabular}{llllll}
\hline Treatment & $\begin{array}{l}\text { Peak Force } \\
(\mathrm{N})\end{array}$ & $\begin{array}{l}\text { Ultimate Stiffness } \\
(\mathrm{N} / \mathrm{s})\end{array}$ & $\begin{array}{l}\text { Bending Failure } \\
\text { Energy }(\mathrm{N} . \mathrm{s})\end{array}$ & $\begin{array}{l}\text { Ultimate Bending } \\
\text { Stress }\left(\mathrm{N} / \mathrm{mm}^{2}\right)\end{array}$ & $\begin{array}{l}\text { Young's Modulus } \\
\left(\mathrm{N} / \mathrm{mm}^{2}\right)\end{array}$ \\
\hline$\underline{\text { Femur }}$ & & & & \\
MHC & $220.67 \pm 12.49$ & $471.70 \pm 42.32^{\mathrm{b}}$ & $5.74 \pm 0.48$ & $85.23 \pm 4.04^{\mathrm{a}}$ & $548.78 \pm 39.90^{\mathrm{a}}$ \\
MHR & $206.85 \pm 10.91$ & $469.94 \pm 28.54^{\mathrm{b}}$ & $4.71 \pm 0.75$ & $78.59 \pm 3.28^{\mathrm{a}}$ & $542.12 \pm 38.20^{\mathrm{a}}$ \\
OHC & $190.65 \pm 9.29$ & $613.12 \pm 41.91^{\mathrm{a}}$ & $4.10 \pm 0.75$ & $54.57 \pm 2.96^{\mathrm{b}}$ & $470.06 \pm 29.32^{\mathrm{b}}$ \\
OHR & $217.36 \pm 12.57$ & $604.37 \pm 42.41^{\mathrm{a}}$ & $4.61 \pm 0.53$ & $62.06 \pm 3.35^{\mathrm{b}}$ & $463.69 \pm 33.87^{\mathrm{b}}$ \\
& & & & & \\
Tibia & & & & & \\
MHC & $146.07 \pm 5.10^{\mathrm{b}}$ & $352.25 \pm 31.10$ & $4.32 \pm 0.64$ & & \\
MHR & $134.14 \pm 6.89^{\mathrm{b}}$ & $311.22 \pm 29.86$ & $3.85 \pm 0.48$ & $112.61 \pm 9.74$ & $737.15 \pm 59.44$ \\
OHC & $174.38 \pm 19.79^{\mathrm{a}}$ & $398.61 \pm 41.64$ & $4.49 \pm 0.87$ & $133.41 \pm 22.80$ & $726.17 \pm 81.35$ \\
OHR & $160.18 \pm 16.27^{\mathrm{a}}$ & $372.71 \pm 42.58$ & $5.40 \pm 1.21$ & $124.50 \pm 18.81$ & $661.88 \pm 73.98$ \\
\hline
\end{tabular}

${ }^{\S}$ Values are expressed as the mean \pm SEM of $n=12-14$ bones/group. Different letters a, $b$, within the same column indicate significant differences at $P<0.05$ with aging by two-way ANOVA followed by Tukey's test. 
Table 10. Plasma measurements of bone formation, inflammation, and oxidative stress in mature and old hindlimb suspended male rats provided resveratrol or no resveratrol supplementation ${ }^{\S}$

\begin{tabular}{lllllll}
\hline Treatment & $\begin{array}{l}\mathrm{Ca} \\
(\mathrm{mg} / \mathrm{dL})\end{array}$ & $\begin{array}{l}\mathrm{P} \\
(\mathrm{mg} / \mathrm{dL})\end{array}$ & $\begin{array}{l}\text { ALP } \\
(\mathrm{U} / \mathrm{L})\end{array}$ & $\begin{array}{l}\text { Total Antioxidant } \\
(\mathrm{mM} / \text { Trolox })\end{array}$ & $\begin{array}{l}\text { TBARS } \\
(\mu \mathrm{M} \text { MDA })\end{array}$ & $\begin{array}{l}\text { CRP } \\
(\mathrm{mg} / \mathrm{mL})\end{array}$ \\
\hline MHC & $13.40 \pm 6.27^{\mathrm{a}}$ & $10.16 \pm 0.33^{\mathrm{a}}$ & $203.29 \pm 15.87^{\mathrm{a}}$ & $1.22 \pm 0.46$ & $4.51 \pm 0.05^{\mathrm{a}, \mathrm{x}}$ & $0.51 \pm 0.15^{\mathrm{b}}$ \\
MHR & $13.21 \pm 0.82^{\mathrm{a}}$ & $11.21 \pm 0.72^{\mathrm{a}}$ & $221.29 \pm 20.64^{\mathrm{a}}$ & $2.02 \pm 0.76$ & $4.99 \pm 0.18^{\mathrm{a}, \mathrm{w}}$ & $1.14 \pm 0.53^{\mathrm{b}}$ \\
OHC & $11.31 \pm 1.09^{\mathrm{b}}$ & $6.71 \pm 0.41^{\mathrm{b}}$ & $169.43 \pm 20.19^{\mathrm{b}}$ & $1.33 \pm 0.50$ & $4.03 \pm 0.20^{\mathrm{b}, \mathrm{y}}$ & $3.46 \pm 0.49^{\mathrm{a}}$ \\
OHR & $11.53 \pm 0.72^{\mathrm{b}}$ & $7.19 \pm 0.43^{\mathrm{b}}$ & $160.00 \pm 6.96^{\mathrm{b}}$ & $1.38 \pm 0.52$ & $3.56 \pm 0.13^{\mathrm{b}, \mathrm{z}}$ & $2.39 \pm 0.71^{\mathrm{a}}$ \\
\hline
\end{tabular}

${ }^{\S}$ Values are expressed as the mean \pm SEM of $n=6$-7/group. Different letters $a, b$, within the same column indicate significant differences at $P<0.05$ with aging by two-way ANOVA followed by Tukey's test. Different letters $\mathrm{x}$, y, within the same column indicate significant differences at $P<0.05$ with resveratrol supplementation by two-way ANOVA followed by Tukey's test.

$\mathrm{Ca}=$ calcium, $P=$ phosphorus, $\mathrm{AL} P=$ Alkaline phosphatase, $\mathrm{TBARS}=$ Thiobarbituric acid reactive substances, $\mathrm{CR} P=\mathrm{C}-\mathrm{reactive}$ protein 


\subsection{DISCUSSION}

In Study 1, loss of trabecular bone in the femur and tibia was observed in aging $\mathrm{AMB}$ rats indicated by decreased bone volume, trabecular number, and connectivity with increased trabecular separation and SMI. In old rats, reduced bone formation was indicated by decreased plasma ALP concentration. ALP is associated with bone matrix synthesis prior to mineralization (Cao et al., 2009). Femur and tibia BMC and ash were higher in old compared to mature rats. This was likely due to the greater bone size of the old compared to mature rats. BMC and bone ash corrected for bone size showed that bone mineralization was not decreased in aged 32 month old male rats. In rats, peak femur and tibia BMD tend to occur between the ages of 6 and 21 months (Iida and Fukuda, 2002). Body weight continues to increase until approximately 12 months of age, and long bones continue to increase in length and weight until old age in rats due to non-fusing of the epiphyses in rats (Iida and Fukuda, 2002). In our study, male Fisher Brown Norway rats continued to grow after age 6 months indicated by greater final body mass, femur and tibia length, width, and weight. Therefore, this is important to consider when choosing a rat model to study aging effects on bone.

Bone strength indicated by higher femur and tibia peak force and ultimate stiffness in old compared to mature male rats was also due to greater bone size. Measuring Young's modulus which takes bone size into consideration showed that aging decreased femur and tibia bone strength. Trabecular bone formation may be more indicative of biomechanical competence. Pietschmann et al. (2007) 
observed that tibia trabecular BMD decreased by as much as $48 \%$ between ages 5 and 23 month old in male Sprague-Dawley rats. The authors attributed decreased bone mass to removal of trabecular bone elements. Legrand et al. (2000) observed that trabecular architecture is directly related to vertebral fracture in middle-aged men diagnosed with severe osteopenia. Differences in fractures were observed even in men with identical cortical BMD. In our study, unfavorable bone architecture and decreased strength was observed in the absence of bone mineral loss.

To attenuate age-related bone loss, resveratrol was supplemented at 12.5 $\mathrm{mg} \cdot \mathrm{kg} \mathrm{bw}^{-1} \cdot \mathrm{d}^{-1}$. Other studies have used doses of 10 to $50 \mathrm{mg} \cdot \mathrm{kg} \mathrm{bw}^{-1} \cdot \mathrm{d}^{-1}(\mathrm{Lin}$ et al., 2005; Liu, et al., 2005; Mizutani et al., 2000; Yoshida et al. 2007). In the current study, resveratrol supplementation had no effect on final body weight or femur morphometry. However, tibia length was increased in mature AMB rats. Resveratrol supplements of $20 \mathrm{mg} \cdot \mathrm{kg} \mathrm{bw}^{-1} \cdot \mathrm{d}^{-1}$ had no effects on body weight or long bone growth in young male Sprague-Dawley rats (Juan et al., 2002).

Yoshida et al. (2007) observed an increase in tibia length after 2 weeks of supplemental resveratrol dose of $50 \mathrm{mg} \cdot \mathrm{kg} \mathrm{bw}^{-1} \cdot \mathrm{d}^{-1}$ of resveratrol to young female rats.

In old rats, resveratrol supplementation increased tibia trabecular thickness while having no effects on cortical mineralization in AMB male rats. Most bone effects were observed in the tibia. This may be due to the rapid growth of the tibia compared to the femur (Davenport, 1933). In the current study, reduced $\mathrm{BMC}$ in old rats may be due to resveratrol acting as a pro-oxidant. In vitro, 
oxidized lipids inhibit osteoblast differentiation (Parhami et al., 1997). However, in our study resveratrol supplementation had no effect on plasma TBARS in old rats indicating resveratrol did not act as a lipid pro-oxidant.

Turrens et al. (1997) found no effects of resveratrol on serum TBARS in rats at doses of 20 and $40 \mathrm{mg} \cdot \mathrm{kg} \mathrm{bw}^{-1} \cdot \mathrm{d}^{-1}$ for 21 days. In our study, plasma TBARS was lower in old compared to mature rats; however, inflammation was greater in old rats indicated by higher plasma CRP compared to mature rats. Ding et al. (2007) reported that high-sensitivity (hs)-CRP was adversely associated with total body BMD in men and women (between age 52-78). Resveratrol supplementation of young female rats has been shown to protect against ovariectomy-induced loss of femur BMD after 13 weeks of $45 \mathrm{mg} \cdot \mathrm{kg} \mathrm{bw}^{-1} \cdot \mathrm{d}^{-1}$ (Lin et al., 2005) and after 12 weeks of $0.7 \mathrm{mg} \cdot \mathrm{kg} \mathrm{bw}^{-1} \cdot \mathrm{d}^{-1}$ (Liu, et al., 2005). Therefore, a longer duration of resveratrol supplementation may be required to attenuate bone mineral loss in aging male rats.

In Study 1, the only significant effect of resveratrol on age-related bone loss was the attenuation of loss of trabecular bone. In general, trabecular bone is more responsive than cortical bone during aging because trabecular bone is more actively remodeled due to the larger surface to volume ratio (Morgan et al., 2008). We were also interested in the potential effect of resveratrol on cortical bone. HLS induces significant bone loss. Allen and Bloomfield (2002) observed a greater impact of HLS on cortical than on trabecular bone in age 6 month old male rats. In addition, aging individuals have higher incidence of mechanical unloading due to inactivity and/or bed rest. Therefore, in Study 2 rats were HLS. 
HLS of aging rats resulted in loss of femur and tibia trabecular bone indicated by decreased bone volume, trabecular number, and connectivity with increased trabecular separation and SMI. HLS of old rats also decreased BMD, but had no effect on bone growth. Measurements such as UBS and Young's modulus, that take bone size into account showed decreased femur strength in old compared to mature rats. Similarly, Smith et al. (1975) reported increased fracture risk with age-related loss of bone mineral.

Decreased lipid peroxidation indicated by reduced plasma TBARS was observed in old rats provided resveratrol. However, plasma TBARS was higher in mature rats provided resveratrol compared to no resveratrol. Therefore, an increase in lipid peroxidation may have contributed to decreased tibia calcium and phosphorus content in mature rats provided resveratrol.

In mature HLS rats, resveratrol supplementation reduced tibia calcium and phosphorus content. In contrast, Liu et al. (2005) reported that resveratrol protected bone calcium content in ovariectomy rats. Resveratrol's protective role in bones may be sex- or age-specific. Considering the pleiotropic effects of resveratrol, it is not surprising that there are a variety of outcomes. To our knowledge no other studies have investigated resveratrol's effects on bone in aging male rats. 


\subsection{SUMMARY AND CONCLUSIONS}

In summary, resveratrol supplementation appeared to have age-specific effects. Therefore, it is important to consider the rat strain when studying agerelated bone loss. Wang et al. (2001) reported that bone loss began at age nine months in male Sprague-Dawley rats. In our study bone growth continued at age 32 months. Trabecular but not cortical bone was lost in aging male Fischer Brown Norway rats.

Resveratrol supplementation attenuated loss of trabecular bone in old AMB rats, but increased bone mineral loss in mature HLS rats. This may have occurred because resveratrol supplementation was observed to decrease oxidation in old but not mature HLS male rats. Mature rats subjected to HLS and provided resveratrol supplementation had increased oxidation and reduced tibia $\mathrm{Ca}$ and $\mathrm{P}$ content. Based on the study results, resveratrol supplementation is currently not recommended for the prevention of age-related bone loss. 


\subsection{REFERENCES}

Allen MR, Bloomfield S. Hindlimb unloading has a greater effect on cortical compared with cancellous bone in mature female rats. J Appl Physiol. 2003; 94: 642-650.

Basu S, Michaelsson K, Olofsson H, Johansson S, lhus H. Association between oxidative stress and bone mineral density. Biochem Biophys Res Commun. 2001; 288: $275-279$.

Bauer DC, Orwoll ES, Fox KM. Aspirin and NSAID use in older women: effect of bone mineral density and fracture risk. Study of Osteoporotic Fractures Research Group. J Bone Miner Res. 1996; 11: 29-35.

Bhupathiraju SN. Alekal DL, Steward JW, Hanson LN, Shedd KM, Reddy MB, Hanson, KB, Van Loan MD, Genschel U, Koehler KJ. J Clin Densitom. 2007; 10: 395-403.

Boissy PA, Andersen TL, Abdallah BM, Kassem M, Plesner T, Delaisse J. Resveratrol inhibits myeloma cell growth, prevents osteoclast formation, and promotes osteoblast differentiation. Cancer Res. 2005; 65: 9943-9952.

Bu SY, Lerner M, Stoecker BJ, Boldrin E, Brackett DJ, Lucas EA, Smith BJ. Dried plum polyphenols inhibit osteoclast ogenesis by downregulating NFATc1 and inflammatory mediators. Calcif Tissue Int. 2008; 82: 475-488.

Cao JJ, Gregoire BR, Gao H. High-fat diet decreases cancellous bone mass but has no effect on cortical bone mass in the tibia in mice. Bone. 2009; 44: 10971104.

Cauley JA, Danielson ME, Boudreau RM, Forrest KY, Zmuda JM, Pahor M, Tylaysky FA, Cummings SR, Harris TB, Newman AB. Inflammatory markers and incident fracture risk in older men and women: the health aging and body composition study. J Bone Miner Res. 2007; 22: 1088-95

Dai Z, Li Y, Quarles LD, Song T, Pan W, Zhou H, Xiao Z. Resveratrol enhances proliferation and osteoblastic differentiation in human mesenchymal stem cells via ER-dependent ERK1/2 activation. Phytomedicine. 2007; 14: 806-814.

Davenport CB. The crural index. Amer J Phys Anthropology. 1933; 17: 333-353.

Dawson AB. The age order of epiphyseal union in the long bones of the albino rat. Anat Rec 1925; 31:1-17. 
Ding C, Parameswaran V, Udayan R, Burgess J, Jones G. Circulating levels of inflammatory markers predict change in bone mineral density and resorption in older adults: a longitudinal study. J Clin Endocrin and Metab. 2007; 22: 1088-95

Feghali CA, Wright TM. Cytokines in acute and chronic inflammation. Frontiers in Bioscience. 1997; 2:12-26.

Franceschi RT, Iyer BS, Cui Y. Effects of ascorbic acid on collagen matrix formation and osteoblast differentiation in murine MC3T3-E1 cells. J Bone Miner 1994; 6: 843-54.

Fremont L. Biological effects of resveratrol. Life Sci. 2000; 66: 663-673.

Garrett RO, Boyce BF, Oreffo R, Bonewald L, Poser J, Mundy GR. Oxygenderived free radicals stimulate osteoclastic bone resorption in rodent bone in vitro and in vivo. J Clin Invest. 1990; 85:632-639.

Gilbert L, He X, Farmer P, Boden S, Kozlowski M, Rubin J, Nanes MS. Inhibition of osteoblast differentiation by tumor necrosis factor- $\alpha$.

Endocrinology. 2000; 141: 3956-3964.

Goswami SK Das DK. Resveratrol and chemoprevention. Cancer Lett. 2009.

Gronholz JM. Prevention, diagnosis, and management of osteoporosis-related fracture: a multifactoral osteopathic approach. J Amer Osteopath Assoc. 2008; 108: 575-585.

Gruntmanis U. Male osteoporosis: deadly, but ignored. Amer J Med Sci. 2007; 333: 85-92.

Habauzit V, Horcajada M. Phenolic phytochemicals and bone. Phytochem Rev. 2008; 7: 313-344)

Hermizi H, Faizah O. Beneficial effects of tocotrienol and tocopherol on bone histomorphometric parameters in Sprague-Dawley male rats after nicotine cessation. Calcif Tissue Int. 2009; 84:64-74.

Iida H, Fukuda S. Age-related changes in bone mineral density, cross-sectional area and strength at different skeletal sites in male rats. $J$ Vet Med Sci. 2002; 64: 29-34)

Jee WS, Ma Y. Animal models of immobilization osteopenia. Morphologie. 1999; 83: 25-34.

Juan ME, Vinardell MP, Planas JM. The daily oral administration of high doses of trans-resveratrol to rats for 28 days is not harmful. J Nutr. 2002; 132: 257-260. 
Kaur G, Rao LVM, Agrawal A, Pendurthi, UR. Effect of wine phenolics on cytokine-induced C-reactive protein expression. J Thromb Haemost. 2007; 5: 1309-17.

Kiebzak GM, Beinart GA, Perser K, et al. Understanding treatment of osteoporosis in men with hip fracture. Arch Intern Med. 2002 162; 2217-2222.

King AC, Rejeski WJ, Buchner DM. Physical activity interventions targeting older adults: a critical review and recommendations. Am J Prev Med. 1998; 15: 316-333.

Klein DC, Raisz LG. Prostaglandins: stimulation of bone resorption in tissue culture. Endocrinology. 1970; 86:1436-1440.

Kopp P. Resveratrol, a phytoestrogen found in red wine. A possible explanation for the conundrum of the 'French paradox'? Eur Endocrinol. 1998; 138: 619-620.

Lafage-Proust MH, Collet P, Dubost JM, Larche N, Alexandre C, and Vico L. Space-related bone mineral redistribution and lack of bone mass recovery after reambulation in young rats. Am J Physiol. 1998; 274: 324-334.

LeBlanc AD, Spector ER, Evans HJ, Sibonga JD. Skeletal responses to space flight and the bed rest analog: a review. J Musculoskelet Neuronal Interact. 2007; 7: 33-47.

Legrand E, Chappard D, Pascaretti C, Duquenne M, Krebs S, Rohmer V, Basle MF, Audran M. Trabecular bone microarchitecture, bone mineral density, and vertebral fractures in male osteoporosis. J Bone Miner Res. 2000; 15: 13-19.

Leonard SS, Xia C, Jiang BH, Stinefelt B, Klandorf H, Harris GK, and Shi X. Resveratrol scavenges reactive oxygen species and effects radical-induced cellular responses. Biochem and Biophys Res Comm. 2003; 309: 1017-1026.

Lin Q, Huang Y, Xiao B, Ren G. Effects of resveratrol on bone mineral density in ovariectomized rats. IJBS. 2005; 1: 76-81.

Liu JP, Li WX, Yu B, Huang J, Sun J, Huo JS, Liu V. Effects of trans-resveratrol from polygonum cuspidatum on bone loss using the ovariectomized rat model. $J$ Med Food. 2005; 8: 14-19.

Magnus K, Nordqvist V, Karlsson V. Physical activity increases bone mass during growth. Food and Nutr Research. 2008.

Manolagas SC, Jilka V. Bone marrow, cytokines, and bone remodeling. New England J of Med. 1995; 332: 305-311. 
Marier J, Vachon P, Gritsas A, Zhang J, Moreau J, Ducharme MP. Metabolism and disposition of resveratrol in rats: extent of absorption, glucuronidation, and enterohepatic recirculation evidenced by a linked-rat model. J Pharm and Exp Therapeutics. 2002; 302: 369-373.

Martinez J, Moreno JJ. Effect of resveratrol, a natural polyphenolic compound, on reactive oxygen species and prostaglandin production. Biochem Pharm. 2000; 59: $865-870$.

Mazess RB, Barden HS, Bisek JP, Hanson J. Dual-energy x-ray absorptiometry for total-body and regional bone-mineral and soft-tissue composition. Am J Clin Nutri. 1990; 51: 1106-1112.

Mizutani K, Ikeda K, Kawai Y, Yamori Y. Resveratrol stimulates the proliferation and differentiation of osteoblastic MC3T3-E1 Cells. Biochem and Biophys Res Comm. 1998; 253: 856-863.

Mizutani K, Ikeda K, Kawai Y, Yamori Y. Resveratrol attenuates ovariectomyinduced hypertension and bone loss in stroke-prone spontaneously hypertensive rats. J Nutr Sci Vitaminol. 2000; 46: 78-83.

Morey-Holton ER, Globus V. Hindlimb unloading rodent model: technical aspects. J Appl Physiol. 2002; 92: 1367-1377.

Morgan EF. Barnes GI, Einhorn TA. The bone organ system: form and function. Osteoporosis. 2008; 3: 3-25.

Morton DJ, Barrett-Connor EL, Schneider DL. Vitamin C supplement use and bone mineral density in postmenopausal women. J Bone Miner Res. 2001; 16: $135-40$.

Mundy GR. Cytokines and growth factors in the regulation of bone remodeling. $J$ Bone Miner Res. 1993; 8: 505-510.

Norrdin RW Jee WS, High WB. Review: the role of prostaglandins in bone in vivo. Prostaglandins Leukot Essent Fatty Acids. 1990; 41:139-149.

Parhami F, Morrow A, Balucan J, Leitinger N, Watson A, Tintut, Y, Berliner J, Demer L. Lipid oxidation products have opposite effects on calcifying vascular cell and bone cell differentiation. Arterio Thromb and Vasc Bio. 1997; 17:680687.

Pervaiz S. Resveratrol: from grapevines to mammalian biology. FASEB J. 2003; 17: 1975-1985. 
Pietschmann P, Skalicky M, Kneissel M, Rauner M, Hofbauer G, Stupphann D, Viidik A. Bone structure and metabolism in a rodent model of male senile osteoporosis. Exp Gerontology. 2007; 42: 1099-1108.

Raisz LG. Potential impact of selective cyclooxygenase- 2 inhibitors on bone metabolism in health and disease. Amer J of Medicine. 2001; 110: 43S-45S.

Raisz LG. Pathogenesis of osteoporosis: concepts, conflicts, and prospects. $J$ Clin Invest. 2005; 115: 3318-3325.

Reginster JY, Burlet N. Osteoporosis: a still increasing prevalence. Bone. 2006; 38: 4-9.

Ross M. Length of life and nutrition in the rat. J Nutr. 1975; 61: 197-210.

Sanchez-Rodriguez MA, Ruiz-Ramos M, Correa-Munoz E, Mendoz-Nunez VM. Oxidative stress as a risk factor for osteoporosis in elderly Mexicans as characterized by antioxidant enzymes. BMC Musculoskeletal Disorders. 2007; 8: 124.

Smith BJ, Lucas EA, Turner RT, Evans GL, Lerner MR, Brackett DJ, Stoecker $\mathrm{BJ}$, Arjmandi BH. Vitamin E provides protection for bone in mature hindlimb unloaded male rats. Calc Tissue Int. 2005; 76: 272-279.

Smith DM, Khairi MR, Johnston CC. The loss of bone mineral with aging and its relationship to risk of fracture. J Clin Invest. 1975; 56 311-318.

Spence A. Basic Human Anatomy. 3rd Edition. Redwood City, California: Benjamin-Cummings Pub Co, 1990.

Peyrin F, Salome M, Cloetens P, Laval-Jeantet AM, Ritman E, Ruegsegger P. Micro-CT examinations of trabecular bone samples at different resolutions: 14, 7 and 2 micron level. Technology and Health Care. 1998; 6: 391-401.

Tou JC, Foley A, Yuan YV, Arnaud S, Wade CE, Brown M. The effect of ovariectomy combined with hindlimb unloading and reloading on the long bones of mature Sprague-Dawley rats. Menopause. 2008; 15: 494-502

Turner $\mathrm{CH}$. Biomechanics of bone: Determinants of skeletal fragility and bone quality. Osteoporosis Int. 2002; 13: 97-104.

Turrens JF, Lariccia J, Nair MG. Resveratrol has no effect on lipoprotein profile and does not prevent peroxidation of serum lipids in normal rats. Free Radic Res. 1997; 27: 557-62. 
Vico L, Bourrin S, Very JM, Radziszowska M, Collet P, Alexandre C. Bone changes in 6-mo-old rats after head-down suspension and a reambulation period. $\mathrm{J}$ Appl Physiol. 1995; 79: 1426-1433.

Vidavalur R, Otani H, Singal PK, Maulik N. Significance of wine and resveratrol in cardiovascular disease: French paradox revisited. Ex Clin Cardiol. 2006; 11: 217-225.

Voss P, Siems W. Clinical oxidation parameters of aging. Free Rad Res. 2006; 40: 1339-1349.

Wang L, Banu J, McMahan CA, Kalu DN. Male rodent model of age-related bone loss in men. Bone. 2001; 29:141-8.

Wattel A, Kamel S, Mentaverri R, Lorget F, Prouillet C, Petit JP, Fardelonne P, Brazier M. Potent inhibitory effect of naturally occurring flavonoids quercetin and kaempferol on in vitro osteoclastic bone resorption. Biochem Pharmacol. 2003; 65: 35-42.

Yoshida Y, Shioi T, Izumi T. Resveratrol ameliorates experimental autoimmune myocarditis. Circ J. 2007; 71: 397-404.

Yuan YV, Kitts DD. Estimation of dietary calcium utilization in rats using a biomechanical functional test. Food Chemistry. 1992; 44: 1-7.

Zioupos P, Currey JD. Changes in the stiffness, strength, and toughness of human cortical bone with age. Bone. 1998; 22: 57-66. 